\title{
Article
}

\section{Text messages to reduce depressive symptoms: Do they work and what makes them effective? A systematic review}

Cox, Katherine L., Allida, Sabine M. and Hackett, Maree

Available at http://clok.uclan.ac.uk/35158/

Cox, Katherine L., Allida, Sabine M. and Hackett, Maree ORCID: 0000-00031211-9087 (2020) Text messages to reduce depressive symptoms: Do they work and what makes them effective? A systematic review. Health Education Journal, 80 (3). pp. 253-271. ISSN 0017-8969

It is advisable to refer to the publisher's version if you intend to cite from the work. https://doi.org/10.1177/0017896920959368

For more information about UCLan's research in this area go to http://www.uclan.ac.uk/researchgroups/ and search for <name of research Group>.

For information about Research generally at UCLan please go to http://www.uclan.ac.uk/research/

All outputs in CLoK are protected by Intellectual Property Rights law, including Copyright law. Copyright, IPR and Moral Rights for the works on this site are retained by the individual authors and/or other copyright owners. Terms and conditions for use of this material are defined in the policies page.

\section{CLoK}

Central Lancashire online Knowledge www.clok.uclan.ac.uk

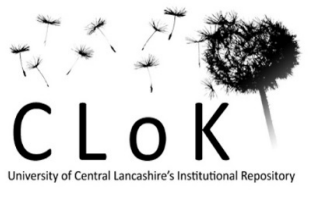




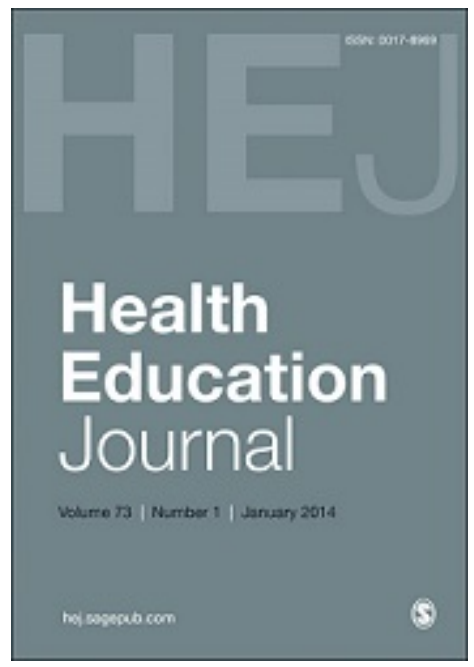

\section{Text messages to reduce depressive symptoms. Do they work and what makes them effective? A systematic review.}

\begin{tabular}{|r|l|}
\hline Journal: & Health Education Journal \\
\hline Manuscript ID & HEJ-20-0034.R2 \\
\hline Kanuscript Type: & Original Article \\
\hline Keywords: & Text message, Depression, SMS, Depressive symptoms, Mobile phone \\
\hline & $\begin{array}{l}\text { Objective } \\
\text { In this systematic review and meta-analysis, we aim to quantify the } \\
\text { effects of text messaging interventions to reduce depressive symptoms } \\
\text { and identify variables that may influence the effectiveness of the } \\
\text { intervention. } \\
\text { Design } \\
\text { Electronic databases including EMBASE, CENTRAL, MEDLINE, CINAHL, } \\
\text { PsycINFO and SCOPUS as well as Clinicaltrials.gov and WHO } \\
\text { International Clinical Trials Registry Platform (ICTRP) were searched for } \\
\text { randomized controlled trials that sent one or more text messages with } \\
\text { health-related content to adults who had been identified by a health care } \\
\text { provider. } \\
\text { Results } \\
\text { Seven trials (9 comparisons), with } 1918 \text { participants were included in the } \\
\text { review, the pooled analysis revealed a borderline statistically significant } \\
\text { reduction in depressive symptom scores between the text messaging } \\
\text { intervention and control groups (Standardised Mean Difference, SMD - } \\
\text { O.27; 95\% CI -0.54 to 0.00; P 0.05) favouring intervention at the end of } \\
\text { intervention. Statistically significant reductions were shown in important } \\
\text { subgroups e.g. where the primary aim of the messages was to reduce } \\
\text { depressive symptoms; in those using the BDI or PHQ-9 questionnaires; } \\
\text { text message content was targeted at mental well-being, mood } \\
\text { improvement and cognitive behavioural therapy information; and the } \\
\text { message frequency was } \geq 2 \text { times per week. } \\
\text { Conclusions } \\
\text { Text messaging has potential as an intervention to reduce depressive } \\
\text { symptoms. The results of this review should be interpreted with caution } \\
\text { due to the methodological limitations of included trials. More research is }\end{array}$ \\
\hline
\end{tabular}


required before recommendations can be made about the routine use of text messaging interventions.

\section{SCHOLARONE \\ Manuscripts}




\section{Text messages to reduce depressive symptoms. Do they work and what makes them} effective? A systematic review

Katherine L Cox ${ }^{a}$, Sabine M Allida ${ }^{a, b}$ and Maree L Hackett ${ }^{a, b, c}$

a Mental Health Division, The George Institute for Global Health, Australia

${ }^{b}$ Faculty of Medicine, UNSW Sydney, Australia

${ }^{c}$ Faculty of Health and Wellbeing, The University of Central Lancashire, United Kingdom

\section{ABSTRACT}

Objective: In this systematic review and meta-analysis, we aimed to quantify the effects of text messaging interventions to reduce depressive symptoms and identify variables that might influence the effectiveness of the intervention.

Design: Electronic databases including EMBASE, CENTRAL, MEDLINE, CINAHL, PsycINFO and SCOPUS as well as Clinicaltrials.gov and the WHO International Clinical Trials Registry Platform (ICTRP) were searched for randomised controlled trials that sent one or more text messages with health-related content to adults who had been identified by a health care provider.

Results: Seven trials (9 comparisons), with 1918 participants were included in the review, the pooled analysis revealed a borderline statistically significant reduction in depressive symptom scores between the text messaging intervention and control groups (Standardised Mean Difference, SMD - $0.27 ; 95 \% \mathrm{Cl}-0.54$ to $0.00 ; \mathrm{P} \mathrm{0.05)}$ favouring intervention at the end of intervention. Statistically significant reductions were shown in important subgroups, e.g. where the primary aim of the messages was to reduce depressive symptoms; in those using the BDI or PHQ-9 questionnaires; where text message content was targeted at mental wellbeing, mood improvement and cognitive behavioural therapy information; and when the message frequency was $\geq 2$ times per week.

Conclusions: Text messaging has potential to reduce depressive symptoms. The results of this review should be interpreted with caution however due to the methodological limitations of included trials. More research is required before recommendations can be made about the routine use of text messaging for the management of depressive symptoms.

Keywords: Text message, depression, SMS, Depressive symptoms, Mobile phone

\section{Corresponding author:}

Katherine L Cox; Mental Health Division, The George Institute for Global Health, PO Box M201 Missenden Road, NSW 2050, Australia

Email: kcox@georgeinstitute.org.au 


\section{Introduction}

Depression can vary in aetiology, presentation and duration. However, common symptoms include sadness, irritability or emptiness, with somatic or cognitive changes that disrupt functioning (American Psychiatric Association, 2018). Depression affects 322 million people globally and depressive disorders are now the largest contributor to non-fatal health loss accounting for over 50 million Years Lived with Disability (World Health Organisation, 2017).

Global estimates suggest up to two thirds of people suffering with a mental disorder never seek treatment from a health professional (The World Health Organization, 2001). This may be partially explained by the lack of safe, effective, low-cost treatments for depressive symptoms in many countries. The primary treatments, psychological therapy and pharmacotherapy, can be resource-intensive, costly and have side effects (Allida et al., 2020). In high income countries where treatments are more readily available, the relatively low rates of seeking treatment (46\%) is likely caused in part by the stigma associated with having a diagnosis and seeking or requiring treatment (The Black Dog Institute, 2015). Stigma is also a barrier in lower resource countries where the highest burden of mental illness lies, compounded by a lack of funding and workforce shortages preventing many from accessing treatment (Bruckner et al., 2011). Confounding these barriers is the intrinsic nature of depressive symptoms which may include a lack of motivation to seek treatment or comply with lengthy courses of drugs or therapy.

In the last twenty years, mobile phones have almost universally integrated into humans' daily lives. To date, there are 7 billion people who live in an area covered by a mobile telephone network (Sood et al., 2016). Ninety percent of adults own a mobile phone in the USA (Hughes and Granger, 2014). Mobile phone ownership in low- and middle-income countries has increased exponentially, faster than any other health, transport or communication infrastructure (Abaza and Marschollek, 2017), positioning mobile phones as accessible devices, quite literally at our fingertips, that offer a highly adaptable (personalisation, frequency, content) communication channel between healthcare professionals and consumers.

Community attitudes to health-related mobile phone delivered interventions have been positive regardless of sex, education level or employment status of participants, including those with symptoms of anxiety or depression. Perceived benefits included convenience and the potential to reduce isolation (Proudfoot et al., 2010). Qualitative interviews with HIV positive participants in an antiretroviral adherence text messaging intervention revealed they derived-derision of greater emotional meanings from simple reminder messages, for example recurring themes of feeling 'cared about' and 'seen' providing a theoretical mechanism of action (Ware et al., 2016). Pearson et al found mobile phone ownership (after adjustments for wealth and education) increased mental wellbeing among rural Ugandans; suggesting that mobile phone interventions that increase social connectedness may also have value in mental health treatment in lower resource countries, remote locations and isolated communities, where such approaches may be more applicable. Other potential mechanisms of text-message intervention efficacy (Dallery et al., 2015) include altering normative beliefs, promoting acceptance of feelings, changing awareness, increasing knowledge and motivation.

In this systematic review and meta-analysis, we aim to summarise the evidence and quantify the effects of using text messaging as an intervention to reduce depressive symptoms for people presenting to healthcare professionals. We also seek to identify what 
variables (content, frequency and personalisation) may influence the effectiveness of text messaging as a health intervention for reducing symptoms of depression.

\section{Methods}

The full systematic review protocol was registered prospectively in PROSPERO: https://www.crd.york.ac.uk/prospero/display_record.php?RecordID=110027

\section{Types of included trials}

Randomised controlled trials (RCTs).

\section{Types of participants}

We included trials of adults aged $\geq 18$ years. Participants were identified for the trial by a healthcare provider, so as to minimise volunteer bias. No exclusions were made on the basis of any reported medical condition among the participants.

\section{Types of interventions}

Text messaging interventions, defined as one or more text messages with health-related content sent to a personal mobile device. The comparator had to be usual care or an attention control-(a small amount of interpersonal interaction without the main intervention). One way (reply not permissible, or participants informed system was one way) and two-way text messaging trials were included, however trials of smartphone applications were excluded.

\section{Types of outcome measures}

The primary outcome was depressive symptoms (mean depression scores) measured using a validated questionnaire at the end of the intervention. Secondary outcomes included depression present/absent: proportion of people not meeting the authors' criteria for depression (not depressed) and adverse events if recorded and reported.

\section{Search methods for identification of trials}

A search strategy was designed with a librarian using terms including (but not limited to) "depress" OR "depression" AND "SMS" OR "text message" OR "short message service". Electronic databases including EMBASE, CENTRAL, MEDLINE, CINAHL, PsycINFO and SCOPUS were searched from 1992 to 18/09/2018. Other sources such as clinicaltrials.gov and WHO International Clinical Trials Registry Platform (ICTRP) registries were also searched. We sought to include all trials since the inception of text messaging (1992). No language restrictions were imposed. The reference lists of relevant trials and reviews were also screened, and further trials were identified for assessment.

\section{Study selection, data extraction and management}

Commented [PA11]: For what ?? management of depressive symptoms??

Commented [KC12R12]: Thank you, now clarified. 
The titles and abstracts identified through the search were screened by two independent reviewers (KC and $\mathrm{SA}$ ) for eligibility for inclusion. Any disagreements were resolved by a third reviewer (MH). Eligible trials were assessed, and the following data were extracted for included trials using a standardised data extraction form:

- Publication details: authors, year and source

- Sample Characteristics: socio-demographics, descriptions of text messages, usual care and depression criteria, country, attrition

- Participants: age, sex/gender, ethnicity, history of depression, co-morbidities, prior and current treatments for depression

- Trial design: randomisation method, sampling mechanism, adherence, follow up length, trial setting.

- Intervention features: type and content of messages, frequency, timing, duration and total number of messages sent

- Effect size: sample size, estimate, standard error, power

- Measurement tools: outcome scales or measurements

- Comparison group details

- Outcome: depression present/absent and mean depression scores at end of treatment (and follow-up data if available) and adverse events (if recorded and reported)

Trials that met all the inclusion criteria with no available outcome data (from the trial report or the authors) could not contribute meaningfully to a pooled estimate of effect. These were regarded as 'dropouts' rather than ineligible, to indicate that they have not been overlooked. Trials with insufficient information to assess whether they met our inclusion criteria were labelled as 'awaiting assessment' and the authors were contacted for further information. Any trials that met our criteria but had not been completed were regarded as 'ongoing'.

\section{Risk of bias and GRADE assessments}

The risk of bias was assessed by two independent reviewers ( $K C$ and SA) using the Cochrane risk of bias tool for randomised controlled trials (Higgins et al., 2019). A judgement of low, high or unclear risk was allocated based on the domains of random sequence generation, allocation concealment, selective reporting, blinding of participants and personnel, blinding of outcome assessment, incomplete outcome data and any other potential sources of bias such as unbalanced variables at baseline. Any disagreement between judgements was discussed and referred to a third reviewer (MH).

Quality of evidence was assessed and adjusted using the five GRADE considerations: trial limitations, consistency of effect, indirectness, imprecision and publication bias (Brożek et al., 2009). An overall rating was given to reflect the level of confidence we have in the strength of evidence collated in this review.

\section{Statistical analysis}

Trial results were pooled and analysed using Review Manager software (Review Manager, 2014). If there were two or more trials the pooled reduction in depressive symptoms was 
calculated using the random-effects approach (DerSimonian and Kacker, 2007). The standardised mean difference (SMD) was calculated for continuous endpoints as different outcome measures were used. Trials with three arms were included as two separate trials with the numbers in the intervention group compared to half the number in the control group. Heterogeneity of the estimates between trial populations was calculated using $\mathrm{I}^{2}$ statistics. Inconsistency in results was categorised as low (I2 0-29), moderate ( $\left.I^{2} 30-49\right)$, substantial ( $1^{2}$ 50-89) and considerable ( $\left.1^{2} 90-100\right)$ (Higgins et al., 2003). Subgroups included analysis by depression questionnaire used, and content and frequency of messages. A sensitivity analysis was run for all trials with depression (yes/no) as the primary outcome and for trials that assessed depression symptoms using validated rating scales.

\section{Results}

\section{Results of the search}

We screened 3,762 titles and abstracts and excluded 3,704 irrelevant records. We retrieved 58 articles for full-text review. After reading the full-texts, the primary reasons for excluding 32 studies were the interventions being mHealth smartphone apps, Internet-based or part of a package of intervention which included text-messages as an adjunct to other components rather than the primary intervention being tested (See Figure 1).

\section{Figure 1 about here}

We included 7 trials ( 9 comparisons, $n=1,918$ participants). Suffoletto et al (2013) and Schlicker et al (2018) were parallel, three armed RCTs (see Table 1 for characteristics of the included trials).

Eight trials are ongoing (Berrouiguet et al., 2014, Chow et al., 2018, Clark et al., 2018, Hartnett et al., 2017, Jiskoot et al., 2017, McCarter et al., 2018, Tandon, 2018, Husain, 2015) and eight awaiting classification (Haas et al., 2017, Boeschoten et al., 2012, Fletcher et al., 2018, Moore et al., 2015, Ohora, 2016, Taleban et al., 2016, Ben-Zeev, 2017, Schueller, 2018). These study authors were contacted to clarify the recruitment methods. Three trials were considered 'dropouts', two studieswolf et al and Spoelstra et at did not report depression scores at the end of the intervention, and one studyPijnenborg et al did not report results by allocation arm (Wolf et al., 2016, Pijnenborg et al., 2010, Spoelstra et al., 2016).

\section{Participants}

Five trials ( 6 comparisons) recruited participants prior to discharge from hospital and one trial recruited from community mental health clinics. Four trials (5 comparisons) required participants to have depression at entry (Agyapong et al., 2017, Agyapong et al., 2012, Hart and Vaccaro, 2017, Schlicker et al., 2018). Participants in tTwo of the trials (3 comparisons) had received anfeceived an inpatient treatment programme consisting of psychotherapy prior to recruitment in the trial (Agyapong et al., 2012, Schlicker et al., 2018). In one trial, people with a variety of diagnosed mood disorders (e.g. depression and anxiety) were included (van den Berg et al., 2015). The conditions of interest in other trials were coronary

Commented [SA16]: Figure 1 indicated in here.

Commented [PA17]: Please indicate where in the main body of the text (Figure 1) - as text - should be placed

Commented [PA18]: Place the dates with the reference here and not at the end of the sentence - so as not to repeat authors' names

Commented [PA19]: ditto

Commented [KC20R20]: thank you, I have corrected.

Commented [PA21]: do you mean Participants in two trials had participated in an inpatient treatment programme ???

Commented [KC22R22]: Correct, now clarified. 
heart disease (Islam et al., 2019), and hazardous drinking (Suffoletto et al., 2013). Participants' mean age ranged from 22 to 58 years and the ratio of women to men was unbalanced in all but two trials (Hart and Vaccaro, 2017, Agyapong et al., 2012). The trials were conducted in the USA (2), Germany (2), Ireland (1), Canada (1) and Australia (1).

\section{Interventions and comparators}

Two comparisons $\forall a n$ den Berg et al and Suffoleto et al (group A)-sent one message a week (van den Berg et al., 2015, Suffoletto et al., 2013) while the other seven comparisinterventions sent two or more. Six interventions had depression as the primary outcome (Schlicker et al., 2018, Agyapong et al., 2017, Agyapong et al., 2012, Hart and Vaccaro, 2017, van den Berg et al., 2015, Suffoletto et al., 2013). Five interventions had usual care as the comparator (Islam et al., 2019, Schlicker et al., 2018, Suffoletto et al., 2013). Two trials sent fortnightly thankyou messages as the attention control (Agyapong et al., 2012, Agyapong et al., 2017) One trial administered telephone calls to both groups and also sent tailored SMS messages to the intervention group with therapy themes (van den Berg et al., 2015). Four comparisons had mental health content in the messages (Agyapong et al., 2017, Agyapong et al., 2012, Schlicker et al., 2018).

Suffoleto et al had two intervention groups, group A received a weekly text-message about alcohol drinking intentions and group B participated in two-way messaging, both compared with usual care (Suffoletto et al., 2013). Schlicker et al group A received standard messages and group $B$ received personalised self-written text-message reminders from inpatient cognitive behaviour therapy (CBT) work, both compared with usual care (Schlicker et al., 2018).

\section{Table 1 about here}

\section{Risk of bias assessment}

A graphical summary of risk of bias assessments as determined by review authors for the included trials is provided in Figure 2.

Allocation. One trial used a systematic method of allocation (alternating week by week) and was assessed as high risk of bias (Schlicker et al., 2018). Neither van den Berg et al (2015) or Hart and Vaccaro (2017) Two studies did not described their method of randomisation and therefore were judged as unclear risk (van den Berg et al., 2015, Hart and Vaccaro, 2017). Only one studytstam et al (2019) gave sufficient detail of their allocation concealment and were rated low risk of bias (Islam et al., 2019). Risk of bias for the remaining trials was unclear.

Blinding. Blinding of participants was not possible due to the nature of the intervention therefore all studies received a high risk of bias judgement for performance bias. One studyAgyapong et al (2012) blinded the outcome assessors, however they reported the blinding was broken in many instances by the participants divulging their allocation group, $t$ Thus it, this study was rated as high risk for detection bias (Agyapong et al., 2012). Suffoletto et al $A$ and BOne study had a self-reported outcome which was were rated as high risk due to potentialfor detection bias_as the outcome assessment was self-reported 
(Suffoletto et al., 2013). Shlicker et al, and van den Berg et alTwo studies did not report blinding of outcome assessment and therefore received an unclear assessment (van den Berg et al., 2015, Schlicker et al., 2018)

Incomplete outcome data. Three trials conducted per--protocol analysis (where only the participants that completed the study are included in the results) potentially leading to bias (Islam et al., 2019, van den Berg et al., 2015, Suffoletto et al., 2013). Schlicker et alOne trial had high attrition across the groups (19.4\% in group A, $24.6 \%$ in group B and $22.3 \%$ in the control group), with the number of imputed values potentially contributing to measurement bias (Schlicker et al., 2018). All were rated as at high risk for incomplete outcome data.

Selective reporting. The frequency of medical contacts and acceptability of the intervention were mentioned in one trial'svan den Berg et al's protocol, however neither outcome was reported in the publication, as such a high risk of bias was awarded for reporting bias (van den Berg et al., 2015). Only one other trial had a published protocol (Islam et al., 2019), as such all others were awarded unclear risk.

Other bias. There were concerns regarding other sources of bias in six studies due to unbalanced variables at baseline (Agyapong et al., 2017, Schlicker et al., 2018, van den Berg et al., 2015, Islam et al., 2019, Hart and Vaccaro, 2017, Suffoletto et al., 2013)

Figure 2 about here

\section{Outcomes}

\section{Primary outcome}

The pooled analysis of seven trials (9 comparisons) (Figure 1) revealed a borderline statistically significant reduction in depressive symptom scores between the text messaging intervention and control groups (Standardised Mean Difference, SMD $-0.27 ; 95 \% \mathrm{Cl}-0.54$ to 0.00 ; $\mathrm{P}$ 0.05) 1,918 participants) at the end of treatment. Substantial heterogeneity was observed $\left(I^{2}=82 \%\right)$.

\section{Secondary outcomes}

Only one trial reported depressed (defined as a PHQ-9 score of 5-27) and not depressed at the end of treatment (Islam et al., 2019). There was a significant difference $(p<0.001)$ in the proportions with depression in the intervention (6.3\%) and control (24.6\%) groups at six months (end of treatment). No trials reported adverse events.

Figure 3 about here

\section{Subgroup analysis}

\section{Content of the messages.}

The subgroup analysis of the three trials ( 4 comparisons) with messages that contained a mental health component demonstrated a statistically significant reduction in depression
Commented [PA23]: no main verb

Commented [KC24R24]: I have added an explanation of 'per-protocol analysis' which is widely used technical term.

Commented [PA25]: place the date with the first mention - and not at the end of the sentence - thereby repeating the authors' name. Please amend throughout the paper

Commented [KC26R26]: corrected. 
symptom scores compared with the control group (SMD $-0.39,95 \% \mathrm{Cl}-0.63$ to $-0.14, \mathrm{n}=353$ participants, $I^{2}=22 \%$ ). The four trials ( 5 comparisons) without a mental health component in their text messaging intervention found no reduction in depression symptom scores in comparison with controls (SMD $-0.15,95 \% \mathrm{Cl}-0.59$ to $0.29, \mathrm{n}=1,515$ participants, $\mathrm{I}^{2}=92 \%$ ). The considerable heterogeneity observed may be due to variations in the intervention and population groups enrolled in the latter trials.

\section{Figure 4 about here}

Frequency of the messages.

The subgroup analysis of 7 comparisons where $\geq 2$ messages were sent per week showed a statistically significant reduction in depressive symptoms (SMD $-0.39,95 \% \mathrm{Cl}-0.65$ to -0.14 $n=1,409$ participants, $\left.I^{2}=69 \%\right)$. The 2 comparisons that delivered $<2$ messages per week showed no statistically significant difference (SMD 0.14, 95\% Cl -0.05 to 0.32, $n=459$ participants).

Figure 5 about here

\section{Sensitivity analysis- Trials with depression as primary outcome}

Sensitivity analysis was performed using 5 trials ( 6 comparisons) with depression as the primary outcome (van den Berg et al., 2015, Agyapong et al., 2017, Hart and Vaccaro, 2017, Schlicker et al., 2018, Agyapong et al., 2012). A statistically significant reduction in mean depression symptom scores was found in the intervention compared to the control groups (SMD -0.30; 95\% Cl -0.52 to $-0.08 ; 439$ participants) at the end of treatment. There was low heterogeneity $\left(I^{2}=19 \%\right)$ but very wide confidence intervals.

\section{Figure 6 about here}

\section{Sensitivity analysis- Trials using standard depression rating scales}

Sensitivity analysis was performed in the four comparisons using the Beck Depression Inventory BDI (Beck et al., 1961, Schlicker et al., 2018, Agyapong et al., 2012, Agyapong et al., 2017) and statistically significant lower depressive symptom scores were found in those in the text messaging intervention group compared to control (SMD $-0.39 ; 95 \% \mathrm{Cl}-0.63$ to -0.14 ; $\mathrm{n}=353$ participants) at the end of treatment. There was low heterogeneity $\left(\mathrm{I}^{2}=22 \%\right)$ but wide confidence intervals.

The pooled result of the four comparisons using the BDI (Beck et al., 1961, Agyapong et al., 2017, Agyapong et al., 2012, Schlicker et al., 2018) combined with one trialtslam who used the PHQ-9 (Kroenke et al., 2001, Islam et al., 2019) was statistically significant for lowering symptoms of depression $(\mathrm{p}<0.0001)$ SMD of $-0.49(95 \% \mathrm{Cl}-0.73$ to $-0.25, \mathrm{n}=1063$ participants) favouring text messaging over control.

\section{Figure 7 about here}

Commented [PA27]: ditto (shift date)

Commented [KC28R28]: corrected so name and date at end for consistency throughout.

\section{Summary of findings}


The overall rating of the quality of evidence of the effectiveness of text-messaging was verylow, as presented in the Summary of Findings (Ttable 2). The evidence from the trials was downgraded in quality due to a high risk of selection and performance bias, heterogeneity, and very wide confidence intervals. We did not assess publication bias due to the small number of included trials (Brożek et al., 2009).

\section{Table 2 about here}

\section{Discussion}

Text messages are often included in health research as part of an intervention package. This review assessed text messaging as a standalone intervention to reduce depressive symptoms. It is useful to understand the value of the individual components of an intervention package for optimum programme design, and this information will be of particular importance in lower resource settings where funding for complex packages of care may not be available.

Data from 7 trials ( 9 comparisons, $n=1,918$ participants) showed text messages on their own were not associated with a reduction indid not reduce depressive symptom scores at the end of the intervention. However statistically significant reductions in depressive symptoms were shown in important subgroups specified a priori e.g. where the primary aim of the messages was to reduce depressive symptoms; in those using the BDI (Agyapong et al., 2017, Agyapong et al., 2012, Schlicker et al., 2018) or PHQ-9 scales (Kroenke et al., 2001, Islam et al., 2019); where text message content was targeted at mental well-being, mood improvement and cognitive behavioural therapy information; and when the message frequency was $\geq 2$ times per week. We found no data on the long-term effects of text messaging interventions or the length of time required to show maximal or sustained response to the receipt of text messages.

Due to the paucity of trials assessing text messaging as a standalone intervention, we also included trials that used other mood rating scales to measure depressive symptoms such as the BSI-18 (Derogatis, 1993) and PHQ-4 (Kroenke et al., 2009). The BSI-18 tool (Derogatis, 1993 ) is a general mood rating scale that measures psychological distress broadly with only six questions focused on depression while the PHQ-4 (Kroenke et al., 2009) is a brief screening tool with two questions on depression and two on anxiety. While we acknowledge that the use of different scales makes comparisons across trials difficult, the sensitivity analysis showed significant results in trials using the BDI or PHQ-9. Thus, we recommend future trials use depression-specific scales when measuring depressive symptoms.

Any indication of benefit must be considered alongside methodological limitations in the included trials e.g. si.e. short duration of the text messaging intervention (from 6 weeks to 6 months), variation in the types of trial participants, the content and frequency of the text messages, and the inadequate reporting of methods in many of the included trials (particularly in the domain of allocation concealment). The overall quality of the evidence was rated as very low due to these limitations and considerable heterogeneity $\left(I^{2}=80 \%\right)$ within and between the trials.

A recently published systematic review evaluating the effectiveness of text messaging, found marginal evidence to support its use as a treatment modality for people with clinical depression (SMD $-0.27,95 \% \mathrm{Cl}-0.48$ to $0.02, \mathrm{p}<0.07 ; 7$ trials, $\mathrm{n}=845$ participants) (Senanayake et al., 2019). In contrast to our review which included adults ( $\geq 18$ years)
Commented [PA29]: please cite this table by number, bot in this way

Commented [KC30R30]: Thank you, table 2 now added to text.

Commented [PA31]: of what? On what?

Commented [KC32R32]: Now added 'evidence of the effectiveness of text-messaging' and 'evidence from the trials'

Commented [PA33]: $\rightarrow$ Were not associated with a reduction in ???

Commented [KC34R34]: Thank you amended as per suggestion.

Commented [PA35]: Text added in OK?

Commented [KC36R36]: Yes, thank you. 
regardless of their baseline depression score, that review included adolescents ( $\geq 13$ years) diagnosed with with depression at baseline (with any accepted tool). In addition, whilst our review was registered prospectively in PROSPERO, their review was retrospectively registered: https://www.crd.york.ac.uk/PROSPERO/RecordID=141100. Most importantly, our review performed sensitivity and subgroup analyses to identify factors in the design of the text messaging interventions that might influence the reduction of depressive symptoms. A Hallet al also undertook a review of systematic reviews into text- messaging for health (no mental health trials were included) and although the results-supported the integration of textmessaging into public health practice, however it was they were unable to recommend optimum intervention characteristics or comment upon longer term effects and called for further research into potential risks and unintended consequences (Hall et al., 2015). A number of the authors of these reviews also called for further research into potential risks and unintended consequences (Hall et al., 2015).

One theory for a potential mechanism of action is the impression of 'connection' between the sender and the recipient of the messages. Social isolation or lack of connectedness, participation and infrequent social contact has been linked to poorer mental health and is a predictor for increased risk of mortality, compared with less socially isolated individuals (Pantell et al., 2013). The feeling of connection established during a text messaging intervention may help reduce social isolation. Based on our findings, a minimum threshold for the frequency of messages is indicative of 2 or more per week.

The stigma associated with mental illness is also a barrier to treatment access for many people. Although not explored in the included studies, anonymity and confidentiality of text messaging interventions are positive characteristics reported in the area of sexual health where stigma is also often a barrier to care (Willoughby and L'Engle, 2015). Qualitative research focusing on the experiences and perceptions of text messaging programmes would further add to the evidence base.

In addition, the smaller group of trials where the primary focus was to reduce depressive symptoms showed benefit. This points to the importance of close alignment between messages received and the outcome being targeted. However, it is important to note that in two trials, participants had undergone underwent an inpatient treatment programme which involved psychotherapy before commencing the text messaging intervention. Thus, the reduction in depressive symptoms may be the result of the combined effect including reinforced learnings from the therapy received during the inpatient treatment programme.

As such, it is possible that the reduction in depressive symptoms observed in these trials was the result of the care received before the intervention or that the text messaging intervention reinforced the learnings from therapy. However, it is difficult to ascertain this.

While we acknowledge that text messaging is not a suitable substitute for mental health service support, it has the potential to augment the current gold standard of care. It is a practical and cost-effective approach, one that is able to reach remote locations and isolated communities. Furthermore, it has the potential to be used in low income countries as a standalone intervention to reduce symptoms of depression as complex packages of interventions come at a higher cost per capita which may be prohibitive in some settings (Hall et al., 2015).

It is important to note that most of the trials were conducted in high-income countries, and text messaging applicability and acceptability in lower resource countries has not been extensively studied. Since text messaging is simple and cost-effective, more research should
Commented [PA38]: clinically diagnosed with depression ???? Or self-reporting depression ??

Commented [KC39R39]: clarified that it was diagnosed using any accepted tool- this is all that is specified in the original paper.

Commented [PA40]: again - take date and referenct to first mention two lines above

Commented [KC41R41]: Thank you now amended so date and name only at the end for consistency throughout.

Commented [PA42]: had undergone

Commented [PA43]: surely, logically, it could have been the result of either $a$ or $b$, or the combined effect of $a+b$ Please re-word more clearly and elegantly 
be conducted in lower resource countries where the highest burden lies in order to bridge this knowledge gap. Nevertheless, factors such as low literacy levels may present a barrier to the use of this mode of treatment.

Further research measuring fidelity to and compliance with the text messaging programme is crucial to ascertain the true effect of the intervention and whether the impact of text messaging remains after a messaging programme has ceased. Adverse event data should be systematically recorded and reported. Interviews with participants could explore other neglected topics to date such as intrusiveness of messaging and participant burden (Berrouiguet et al., 2016).

\section{Limitations}

The inadequate reporting of some trials precluded classification of risk of bias as either low or high risk. This led us to rate some of the trials across the categories at unclear risk of bias. Another limitation is the small number of included trials and participants which contributed to the wide confidence intervals observed in the meta-analysis. These limitations resulted in an overall rating of 'very low' quality of evidence in the summary of findings.

\section{Conclusion}

Statistically significant reductions in depressive symptoms were identified shown where the primary aim of the messages was to reduce depressive symptoms; in those trials using the BDI or PHQ-9 questionnaires; where text message content was targeted at mental wellbeing, mood improvement and cognitive behavioural therapy information; and when the message frequency was $\geq 2$ times per week. These results should be interpreted with caution due to methodological limitations associated with the included trials. More research is required before recommendations can be made about the routine use of text messaging interventions in this area.

\section{Declaration of interest}

MLH is a co-author of one of the included studies.

\section{Funding}

This research received no specific grant from any funding agency in the public, commercial, or not-for-profit sectors. MLH is funded by a National Health and Medical Research Foundation Career Development Fellowship (Level 2), APP1141328 


\section{References}

Please ensure that all references are complete and are set to the correct journal style SAGE Harvard Note - all journal titles should appear in full and the first letter of each word in the title should be capitalised

Abaza, H \& Marschollek, M 2017. mHealth Application Areas and Technology Combinations. Journal of Methods of Information in Medicine, 56, e105-e122.

Agyapong, V, Ahern, S, Mcloughlin, D, et al. 2012. Supportive text messaging for depression and comorbid alcohol use disorder: single-blind randomised trial. Journal of Affective Disorders, 141, 168-176.

Agyapong, V, Juhás, M, Ohinmaa, A, et al. 2017. Randomized controlled pilot trial of supportive text messages for patients with depression. BMC Psychiatry, 17, 286.

Allida, S, Cox, KL, Hsieh, CF, et al. 2020. Pharmacological, psychological, and non-invasive brain stimulation interventions for treating depression after stroke. Cochrane Database of Systematic Reviews.

American Psychiatric Association. 2018. What Is Depression? [Online]. Available: https://www.psychiatry.org/patients-families/depression/what-is-depression [Accessed 18 November 2018].

Beck, AT, Ward, CH, Mendelson, M, et al. 1961. An inventory for measuring depression. Archives of General Psychiatry, 4, 561-571.

Ben-Zeev, D. 2017. NCT03062267: Effectiveness of a Mobile Texting Intervention for People With Serious Mental Illness [Online]. Available: https://clinicaltrials.gov/ct2/show/NCT03062267 [Accessed 10/2018].

Berrouiguet, S, Alavi, Z, Vaiva, G, et al. 2014. SIAM (Suicide intervention assisted by messages): the development of a post-acute crisis text messaging outreach for suicide prevention. BMC Psychiatry, 14, 294.

Berrouiguet, S, Baca-García, E, Brandt, S, et al. 2016. Fundamentals for future mobile-health (mHealth): a systematic review of mobile phone and web-based text messaging in mental health. Journal of Medical Internet Research, 18, e135.

Boeschoten, RE, Dekker, J, Uitdehaag, BM, et al. 2012. Internet-based self-help treatment for depression in multiple sclerosis: study protocol of a randomized controlled trial. $B M C$ Psychiatry, 12, 137.

Brożek, JL, Akl, EA, Alonso-Coello, P, et al. 2009. Grading quality of evidence and strength of recommendations in clinical practice guidelines. Allergy, 64, 669-677.

Bruckner, TA, Scheffler, RM, Shen, G, et al. 2011. The mental health workforce gap in low-and middle income countries: a needs-based approach. Bulletin of the World Health Organization, 89, 184-194.

Chow, CK, Thiagalingam, A, Santo, K, et al. 2018. TEXT messages to improve MEDication adherence and Secondary prevention (TEXTMEDS) after acute coronary syndrome: a randomised clinical trial protocol. BMJ Open., 8, e019463.

Clark, DO, Srinivas, P, Bodke, K, et al. 2018. Addressing people and place microenvironments in weight loss disparities (APP-Me): Design of a randomized controlled trial testing timely messages for weight loss behavior in low income Black and White Women. Contemporary Clinical Trials, 67, 74-80.

Dallery, J, Jarvis, B, Marsch, L, et al. 2015. Mechanisms of change associated with technology-based interventions for substance use. Drug and Alcohol Dependence, 150, 14-23.

Derogatis, LR 1993. Brief Symptom Inventory (BSI). Administration, Scoring, and Procedures Manual, Minneapolis, National Computer Systems.
Commented [KC45]: Thank you all corrected as requested. The Trial registries NCT references are not full publications in journals however I have now added their URL's. 
Dersimonian, R \& Kacker, R 2007. Random-effects model for meta-analysis of clinical trials: an update. Contemporary Clinical Trials, 28, 105-114.

Fletcher, R, May, C, Attia, J, et al. 2018. Text-based program addressing the mental health of soonto-be and new fathers (SMS4dads): Protocol for a randomized controlled trial. JMIR Research Protocols, 7, e37.

Haas, K, Martin, A \& Park, K 2017. Text message intervention (TEACH) improves quality of life and patient activation in celiac disease: a randomized clinical trial. The Journal of Pediatrics., 185, 62-67. e2.

Hall, A, Cole-Lewis, H \& Bernhardt, J 2015. Mobile Text Messaging for Health: A Systematic Review of Reviews. Annual Review of Public Health, 36, 393-415.

Hart, T \& Vaccaro, M 2017. Goal intention reminding in traumatic brain injury: A feasibility study using implementation intentions and text messaging. Journal of Brain Injury, 31, 297-303.

Hartnett, D, Murphy, E, Kehoe, E, et al. 2017. Supportive text messages for patients with alcohol use disorder and a comorbid depression: a protocol for a single-blind randomised controlled aftercare trial. BMJ Open., 7, e013587.

Higgins, J, Savović, J, Page, M, et al. 2019. Chapter 8: Assessing risk of bias in included studies. Journal Cochrane Handbook for Systematic Reviews of Interventions, Version 6.0. Cochrane.

Higgins, J, Thompson, S, Deeks, J, et al. 2003. Measuring inconsistency in meta-analyses. BMJ (Clinical Research Ed.), 327, 557-560.

Hughes, H \& Granger, B 2014. Racial Disparities and the Use of Technology for Self-Management in Blacks with Heart Failure: A Literature Review. Journal Current Heart Failure Reports, 11, 281-289.

Husain, N. 2015. NCT02526355: Development and Assessment of a Mobile Phone Based Intervention to Reduce Maternal Depression and Improve Child Health (TechMother) [Online]. Available: https://clinicaltrials.gov/ct2/show/NCT02526355 [Accessed 10/2018].

Islam, S, Chow, C, Redfern, J, et al. 2019. Effect of text messaging on depression in patients with coronary heart disease: a substudy analysis from the TEXT ME randomised controlled trial. BMJ Open., 9, e022637.

Jiskoot, G, Benneheij, S, Beerthuizen, A, et al. 2017. A three-component cognitive behavioural lifestyle program for preconceptional weight-loss in women with polycystic ovary syndrome (PCOS): a protocol for a randomized controlled trial. Reproductive Health, 14, 34.

Kroenke, K, Spitzer, R \& Williams, J 2001. The PhQ-9. Journal of General Internal Medicine, 16, 606613.

Kroenke, K, Spitzer, RL, Williams, JBW, et al. 2009. An ultra-brief screening scale for anxiety and depression: the PHQ-4. Psychosomatics, 50, 613-621.

Mccarter, D, Demidenko, E \& Hegel, M 2018. Measuring outcomes of digital technology-assisted nursing postpartum: A randomized controlled trial. Journal of Advanced Nursing, 74, 2207 2217.

Moore, D, Poquette, A, Casaletto, K, et al. 2015. Individualized texting for adherence building (iTAB): improving antiretroviral dose timing among HIV-infected persons with co-occurring bipolar disorder. AIDS Behavior, Treatment And Prevention., 19, 459-471.

Ohora, J. 2016. NCT02986945: Community-Partnered Participatory Development of Mobile Interventions [Online]. Available: https://clinicaltrials.gov/ct2/show/NCT02986945 [Accessed 10/2018].

Pantell, M, Rehkopf, D, Jutte, D, et al. 2013. Social isolation: a predictor of mortality comparable to traditional clinical risk factors. American Journal of Public Health, 103, 2056-2062.

Pijnenborg, G, Withaar, F, Brouwer, WH, et al. 2010. The efficacy of SMS text messages to compensate for the effects of cognitive impairments in schizophrenia. British Journal of Clinical Psychology, 49, 259-274. 
Proudfoot, J, Parker, G, Hadzi Pavlovic, D, et al. 2010. Community Attitudes to the Appropriation of Mobile Phones for Monitoring and Managing Depression, Anxiety, and Stress. Journal of Medical Internet Research, 12, e64.

Review Manager 2014. The Nordic Cochrane Centre. The Cochrane Collaboration.

Schlicker, S, Ebert, DD, Middendorf, T, et al. 2018. Evaluation of a text-message-based maintenance intervention for Major Depressive Disorder after inpatient cognitive behavioral therapy. Journal of Affective Disorders, 227, 305-312.

Schueller, S. 2018. NCT03633682: Evaluation of Text Message Engagement Support of Mindfulness Smartphone Applications [Online]. Available: https://clinicaltrials.gov/ct2/show/NCT03633682 [Accessed 10/2018].

Senanayake, B, Wickramasinghe, S, Chatfield, M, et al. 2019. Effectiveness of text messaging interventions for the management of depression: A systematic review and meta-analysis. Journal of Telemedicine and Telecare, 25, 513-523.

Sood, M, Chadda, R \& Singh, P 2016. Mobile health (mHealth) in mental health: Scope and applications in low-resource settings. Medicine and Society, 29, 341-343.

Spoelstra, SL, Given, CW, Sikorskii, A, et al. 2016. Proof of concept of a mobile health short message service text message intervention that promotes adherence to oral anticancer agent medications: a randomized controlled trial. Journal of Telemedicine E-Health., 22, 497-506.

Suffoletto, B, Callaway, CW, Kristan, J, et al. 2013. Mobile phone text message intervention to reduce binge drinking among young adults: study protocol for a randomized controlled trial. Journal of Trials, 14, 93.

Taleban, R, Zamani, A, Moafi, M, et al. 2016. Applications of text messaging, and bibliotherapy for treatment of patients affected by depressive symptoms. International Journal of Preventive Medicine, 7.

Tandon, D. 2018. NCT03420755: Integrating Text Messages Into the Mothers and Babies Course [Online]. Available: https://clinicaltrials.gov/ct2/show/NCT03420755 [Accessed 10/2018].

The Black Dog Institute 2015. Facts \& figures about mental health. Sydney, Australia: The Black Dog Institute.

The World Health Organization 2001. World health report. Mental disorders affect one in four people. Geneva: WHO.

Van Den Berg, N, Grabe, HJ, Baumeister, SE, et al. 2015. A Telephone- and Text Message-Based Telemedicine Concept for Patients with Mental Health Disorders: Results of a Randomized Controlled Trial. Psychotherapy and Psychosomatics, 84, 82-89.

Ware, NC, Pisarski, EE, Tam, M, et al. 2016. The Meanings in the messages: how SMS reminders and real-time adherence monitoring improve antiretroviral therapy adherence in rural Uganda. AIDS (London, England), 30, 1287-1294.

Willoughby, JF \& L'engle, KL 2015. Influence of perceived interactivity of a sexual health text message service on young people's attitudes, satisfaction and repeat use. Health Education Research, 30, 996-1003.

Wolf, M, Kraft, S, Tschauner, $\mathrm{K}$, et al. 2016. User activity in a mobile phone intervention to assist mindfulness exercises in people with depressive symptoms. Mental Health Prevention, 4, 5762.

World Health Organisation 2017. Depression and Other Common Mental Disorders: Global Health Estimates. In: WHO (ed.). Geneva. 
Table 1 Characteristics of the trials included in 'text messaging interventions for reducing symptoms of depression review'

\begin{tabular}{|c|c|c|c|c|c|}
\hline $\begin{array}{l}\text { First author, } \\
\text { year, country }\end{array}$ & $\begin{array}{l}\text { Target condition, study } \\
\text { duration }\end{array}$ & $\begin{array}{c}\text { Sample size, } \\
\text { mean age, } \\
\text { percent male }\end{array}$ & Experimental and control & $\begin{array}{l}\text { Depression tool } \\
\text { (primary/secondary } \\
\text { outcome measure) }\end{array}$ & $\begin{array}{l}\text { Outcomes, Endpoint } \\
\text { timing, Mean (SD) }\end{array}$ \\
\hline $\begin{array}{l}\text { Agyapong et al } \\
2012 \\
\text { Ireland }\end{array}$ & $\begin{array}{l}\text { DSM IV diagnosis of } \\
\text { unipolar depression } \\
\text { and AUD. Completed } \\
\text { an in-patient dual } \\
\text { diagnosis treatment } \\
\text { programme } \\
3 \text { months }\end{array}$ & $\begin{array}{l}54 \text { participants } \\
49 \text { years } \\
46 \%\end{array}$ & $\begin{array}{l}\text { Intervention group: twice daily } \\
\text { supportive text messages } \\
(\mathrm{n}=26) \\
\text { Control group: a fortnightly } \\
\text { thank you text message }(n=28)\end{array}$ & BDI-II (primary) & $\begin{array}{l}\text { End of intervention } \\
\text { Intervention } 8.5( \pm 8.0) \\
(n=196) \\
\text { Control } 16.7( \pm 10.3)\end{array}$ \\
\hline $\begin{array}{l}\text { Agyapong et al } \\
2017 \\
\text { Canada }\end{array}$ & $\begin{array}{l}\text { MDD } \\
3 \text { months }\end{array}$ & $\begin{array}{l}73 \text { participants } \\
\text { Not reported } \\
32 \%\end{array}$ & $\begin{array}{l}\text { Intervention group: twice-daily } \\
\text { supportive text messages } \\
\text { ( } n=35) \text {. } \\
\text { Control group: single text } \\
\text { message every fortnight } \\
\text { thanking them for } \\
\text { participating in the study } \\
(n=38)\end{array}$ & BDI-II (primary) & $\begin{array}{l}\text { End of intervention } \\
\text { Intervention } 20.8( \pm 11.7) \\
\text { Control } 24.9( \pm 11.5)\end{array}$ \\
\hline $\begin{array}{l}\text { Hart and Vaccaro } \\
2017 \\
\text { USA }\end{array}$ & $\begin{array}{l}\text { TBI sustained at least } 6 \\
\text { months prior and at } \\
\text { least mild depression } \\
\text { and/or anxiety } \\
8 \text { weeks }\end{array}$ & $\begin{array}{l}8 \text { participants } \\
29 \text { years } \\
50 \%\end{array}$ & $\begin{array}{l}\text { Intervention group: } \\
\text { individualised reminder } \\
\text { messages that were relevant } \\
\text { to ongoing goals, framed as } \\
\text { implementation intentions }\end{array}$ & BSI-18 (primary) & $\begin{array}{l}\text { End of intervention } \\
\text { Intervention } 53.2( \pm 7.9) \\
\text { Control } 52.5( \pm 11.9)\end{array}$ \\
\hline
\end{tabular}


sent daily by text message

Control group: daily SMS

messages with self-selected

motivational statements

(motivation group, $\mathrm{n}=4$ )

$\begin{array}{lll}\text { Islam et al } & \text { CHD } & 710 \text { participants } \\ \mathbf{2 0 1 9} & & 58 \text { years } \\ \text { Australia } & 6 \text { months } & 82 \%\end{array}$

Intervention group: four text

messages per week that

provided education,

motivation and support on

diet, physical activity, general

PHQ-9 (secondary) End of Intervention

Intervention $1.0( \pm 2.2)$

cardiac education and

smoking, if relevant $(n=352)$

Control group: usual care $(n=358)$

226 participants Intervention group: 81 text

Schlicker et al A Completed inpatient

messages over 10 weeks

BDI-II (primary)

Control $2.9( \pm 3.3)$

$(n=77)$

Control group: usual care

$(n=38)$

End of intervention (6w)

Intervention $15.08( \pm 11.35)$

Control $18.93( \pm 13.50)$

\section{Follow up (10w)}

Intervention $13.06( \pm 10.18)$

Control $18.29( \pm 13.93)$ 


\section{Schlicker et al B}

2018

Germany

treatment for MDD

10 weeks

Suffoletto et al A Aged 18-25 years

2013

USA

presenting to

emergency

departments who

reported hazardous

drinking

9 months
226 participants

44 years

$37 \%$

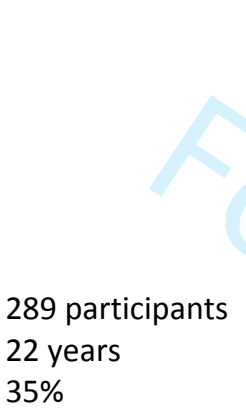

drinking queries (assessing

whether the individual had a

weekend drinking plan). If a

plan to drink was reported

SMS queried whether the

person was willing to set a

goal to limit drinking below

the threshold of 4 drinks for

women ( 5 for men) per

drinking occasion over that weekend) ( $n=196)$

Control group: usual care $(n=93)$

Intervention group: SMS plus feedback including: intention

476 participants

22 years
BDI-II (primary)

End of intervention (6w)

Intervention $16.32( \pm 12.02)$

Control $18.93( \pm 13.50)$

\section{Follow up (10w)}

Intervention $16.30( \pm 11.63)$

Control $18.29( \pm 13.93)$

PHQ-4 (secondary) End of Intervention (3m)

Intervention $2.87( \pm 3.10)$

Control $2.38( \pm 2.69)$

Follow up $(6 \mathrm{~m})$

Intervention $2.95( \pm 3.21)$

Control2.44 ( \pm 2.76$)$

Follow up (9m)

Intervention 2.59 ( \pm 2.09$)$

Control $2.69( \pm 3.15)$ 


$\begin{array}{ll}\text { USA } & \begin{array}{l}\text { emergency } \\ \text { departments who } \\ \text { reported hazardous } \\ \text { drinking }\end{array}\end{array}$

9 months

Van den Berg et
al
2015

2015

Germany

with diagnosed

depression, anxiety

disorder, adjustment
$35 \%$

formation, barrier

identification, general

encouragement, goal setting,

self-monitoring, positive

feedback on performance,

these two-way messages were

based on motivational

interviewing styles. A

sequence of messages sent on

Thursday and another

sequence on Sunday $(n=384)$

Control group: usual care

( $\mathrm{n}=92)$

123 participants

Preparing for discharge

44 years

$22 \%$

disorder or

somatoform disorder Intervention group: telephone
calls and tailored once a week

short text messages $(n=40)$

Control group telephone calls only $(n=42)$

Control $2.38( \pm 2.69)$

\section{Follow up (6m)}

Intervention $2.19( \pm 2.65)$

Control $2.44( \pm 2.76)$

Follow up $(9 \mathrm{~m})$

Intervention $2.11( \pm 2.75)$

Control $2.69( \pm 3.15)$

BSI-18 (primary)

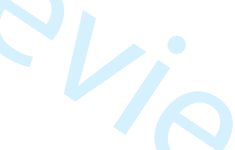

End of treatment

Intervention $6.22( \pm 5.59)$

Control $6.27( \pm 5.75)$

6 months

Abbreviations AUD: alcohol use disorder; DSM IV: Diagnostic and Statistical Manual of Mental Disorders, $4^{\text {th }}$ edition; BDI-II: Beck Depression Inventory, second revision; BSI: Brief symptom index; CBT: Cognitive Behavioural Therapy; CHD: coronary heart disease; m: months; MDD: major depressive disorder; PHQ-4: 4-item Patient Health Questionnaire; PHQ-9: 9-item Patient Health Questionnaire; PROMIS: Patient Reported Outcomes Measurement Information System; RCT: randomised controlled trial; SMS: short message service; TBI: traumatic brain injury; w: weeks. 
Table 2. Summary of findings table

\section{Text messages compared to control for Depression}

Patient or population: People with depression

Setting: Inpatient

Intervention: Text messages

Comparison: Control

\begin{tabular}{|c|c|c|c|c|c|}
\hline \multirow[b]{2}{*}{ Outcomes } & $\begin{array}{l}\text { Anticipated absolute effects* } \\
\qquad(95 \% \mathrm{Cl})\end{array}$ & \multirow{2}{*}{$\begin{array}{c}\text { Relative } \\
\text { effect } \\
(95 \% \text { Cl) }\end{array}$} & \multirow{2}{*}{$\begin{array}{c}\text { № of } \\
\text { participants } \\
\text { (studies) }\end{array}$} & \multirow{2}{*}{$\begin{array}{l}\text { Certainty of } \\
\text { the evidence } \\
\text { (GRADE) }\end{array}$} & \multirow[b]{2}{*}{ Comments } \\
\hline & $\begin{array}{l}\text { Risk with } \\
\text { Text } \\
\text { messages }\end{array}$ & & & & \\
\hline $\begin{array}{l}\text { Depression: mean scores at } \\
\text { end of treatment }\end{array}$ & $\begin{array}{l}\text { SMD } 0.27 \text { SD } \\
\text { lower } \\
\text { (0.54 lower to } \\
0.00 \text { lower) }\end{array}$ & & $\begin{array}{c}1918 \\
\text { (9 RCTs) }\end{array}$ & $\underset{\text { VERY LOW }}{\oplus \bigcirc, \mathrm{O}}$ & \\
\hline $\begin{array}{l}\text { Depression: mean scores at } \\
\text { end of treatment - Beck } \\
\text { Depression Inventory, BDI (high } \\
\text { score = more depressed) }\end{array}$ & $\begin{array}{c}\text { SMD } 0.39 \text { SD } \\
\text { lower } \\
\text { (0.63 lower to } \\
0.14 \text { lower) }\end{array}$ & - & $\begin{array}{c}353 \\
(4 \mathrm{RCTS})\end{array}$ & $\underset{\text { VERY LOW }}{\oplus \bigcirc \bigcirc \mathrm{O}, \mathrm{O}}$ & \\
\hline $\begin{array}{l}\text { Depression: mean scores at } \\
\text { end of treatment - Brief } \\
\text { Symptom Inventory, BSI-18 }\end{array}$ & $\begin{array}{c}\text { SMD } 0 \text { lower } \\
\text { (0.42 lower to } \\
0.41 \text { higher) }\end{array}$ & - & $\begin{array}{c}90 \\
\text { (2 RCTs) }\end{array}$ & $\underset{\text { VERY LOW }}{\oplus \bigcirc, d}$ & \\
\hline $\begin{array}{l}\text { Depression: mean scores at } \\
\text { end of treatment - Patient } \\
\text { Health Questionnaire, PHQ-4 } \\
\text { (high score = more depressed) }\end{array}$ & $\begin{array}{c}\text { SMD } 0.02 \\
\text { higher } \\
\text { (0.24 lower to } \\
0.29 \text { higher) }\end{array}$ & - & $\begin{array}{c}765 \\
\text { (2 RCTs) }\end{array}$ & $\underset{\text { VERY LOW }}{\oplus \bigcirc \bigcirc}$ & \\
\hline $\begin{array}{l}\text { Depression: mean scores at } \\
\text { end of treatment - Patient } \\
\text { Health Questionnaire, PHQ-9 } \\
\text { (higher score }=\text { more } \\
\text { depressed) }\end{array}$ & $\begin{array}{c}\text { SMD } 0.68 \text { SD } \\
\text { lower } \\
\text { (0.83 lower to } \\
0.52 \text { lower) }\end{array}$ & - & $\begin{array}{c}710 \\
(1 \mathrm{RCT})\end{array}$ & $\underset{\text { VERY LOW }}{\oplus \bigcirc \bigcirc \bigcirc}$ & \\
\hline
\end{tabular}

*The risk in the intervention group (and its $95 \%$ confidence interval) is based on the assumed risk in the comparison group and the relative effect of the intervention (and its $95 \% \mathrm{Cl}$ ).

Cl: Confidence interval; SMD: Standardised mean difference

GRADE Working Group grades of evidence

High certainty: We are very confident that the true effect lies close to that of the estimate of the effect

Moderate certainty: We are moderately confident in the effect estimate: The true effect is likely to be close to the estimate of the

effect, but there is a possibility that it is substantially different

Low certainty: Our confidence in the effect estimate is limited: The true effect may be substantially different from the estimate of the effect

Very low certainty: We have very little confidence in the effect estimate: The true effect is likely to be substantially different from the estimate of effect

\section{Explanations}

a. We downgraded the quality of evidence as the studies were rated as high risk for multiple risk of bias domains. 
b. We downgraded the quality of evidence as there is considerable heterogeneity (I= $75 \%$ to $100 \%$ ) observed. c. We downgraded the quality of evidence as the confidence intervals were wide.

d. We downgraded the quality of evidence as the confidence intervals were very wide.

e. We downgraded the quality of evidence as there are only 2 studies with $<100$ participants contributing to the analysis. 
Figure 1. PRISMA flow diagram.

Please can we have editable figures, we cannot reproduce the figures in the format currently provided?

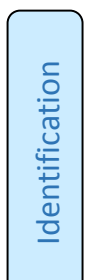

Records identified through database searching (Medline, CINAHL, Embase, PsycINFO and Scopus) $(n=3688)$
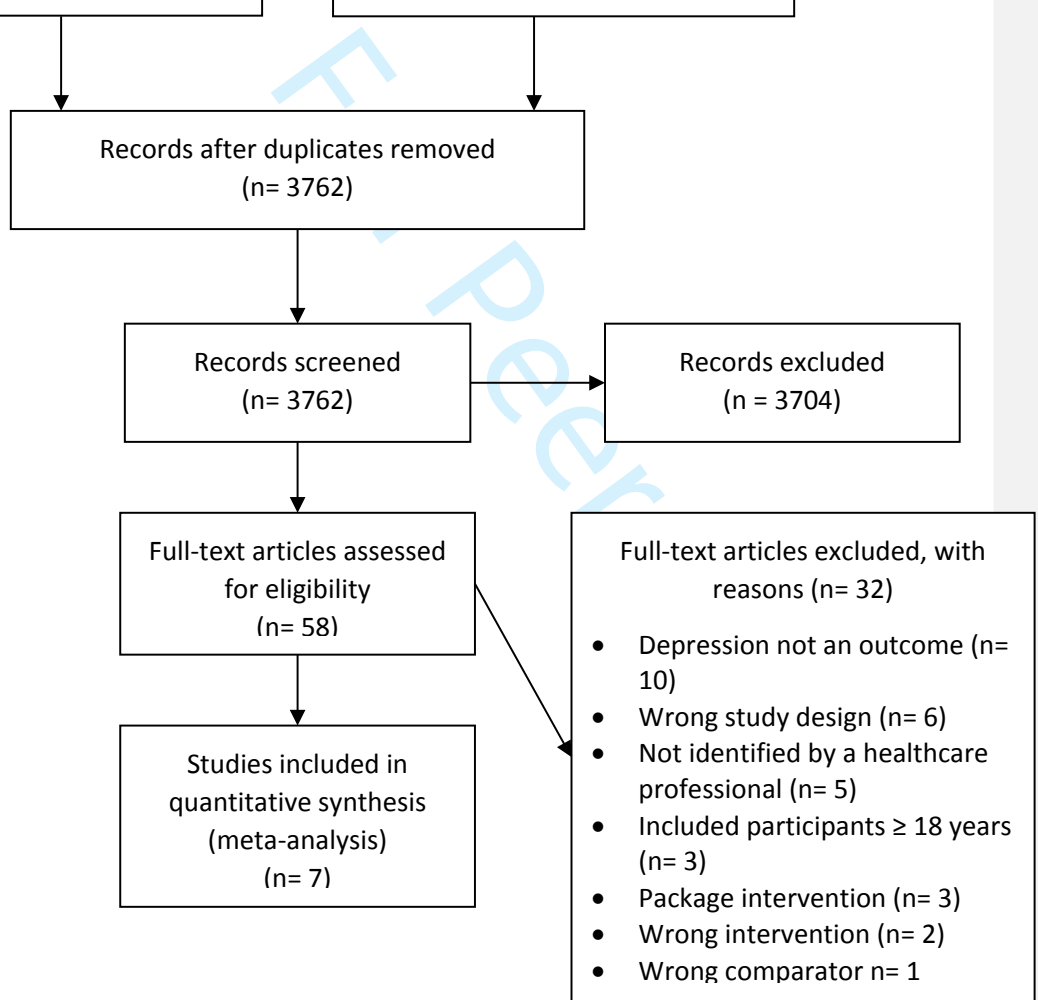

Additional records identified through other sources (systematic reviews, reference list and clinical trial registries) $(n=74)$

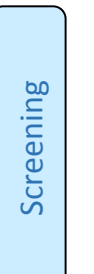

Studies included in antitative synthesis

Wrong comparator $n=1$
Commented [KC46]: Thank you please find editable (Word) Prisma 
Figure 2. Risk of bias summary: review authors' judgements about each risk of bias item for each included study.

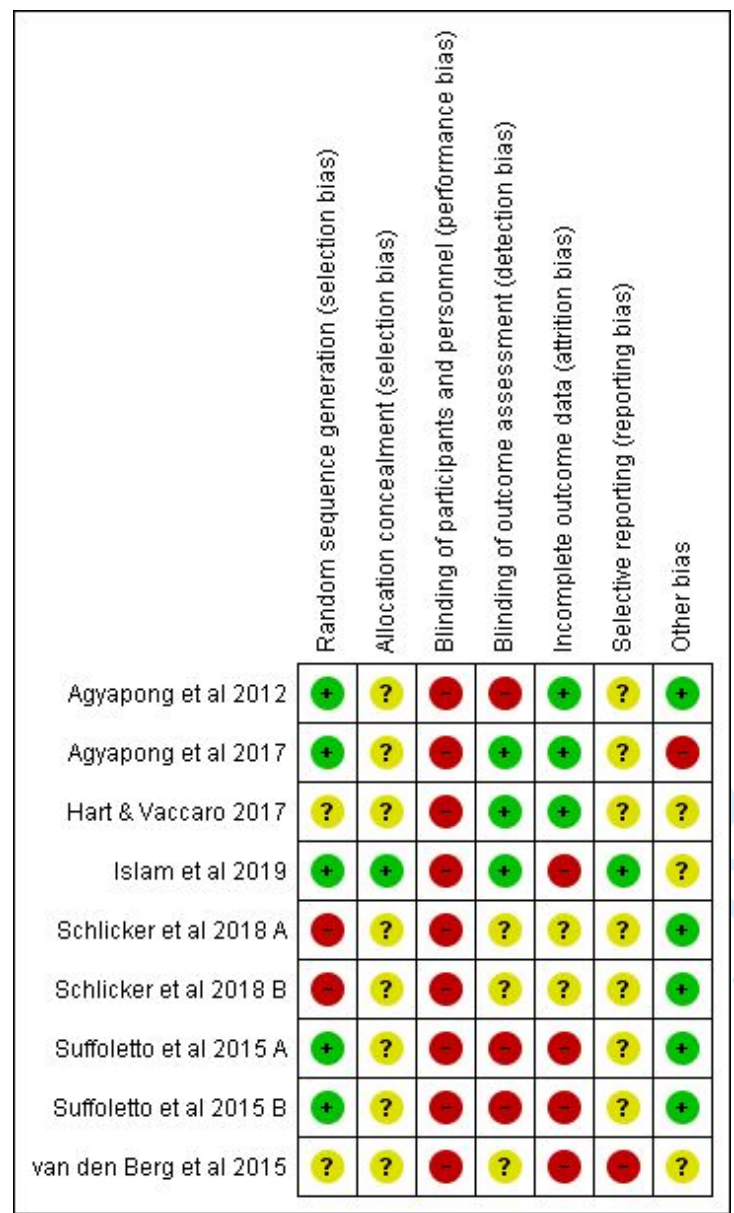

Legend: Green + represents low risk; yellow? represents unclear risk; red - represents high risk.

Other bias relates to whether a published trial protocol was available. 
Figure 3. Forest plot of comparison: Text messages vs. control, Depression: mean scores at end of treatment.

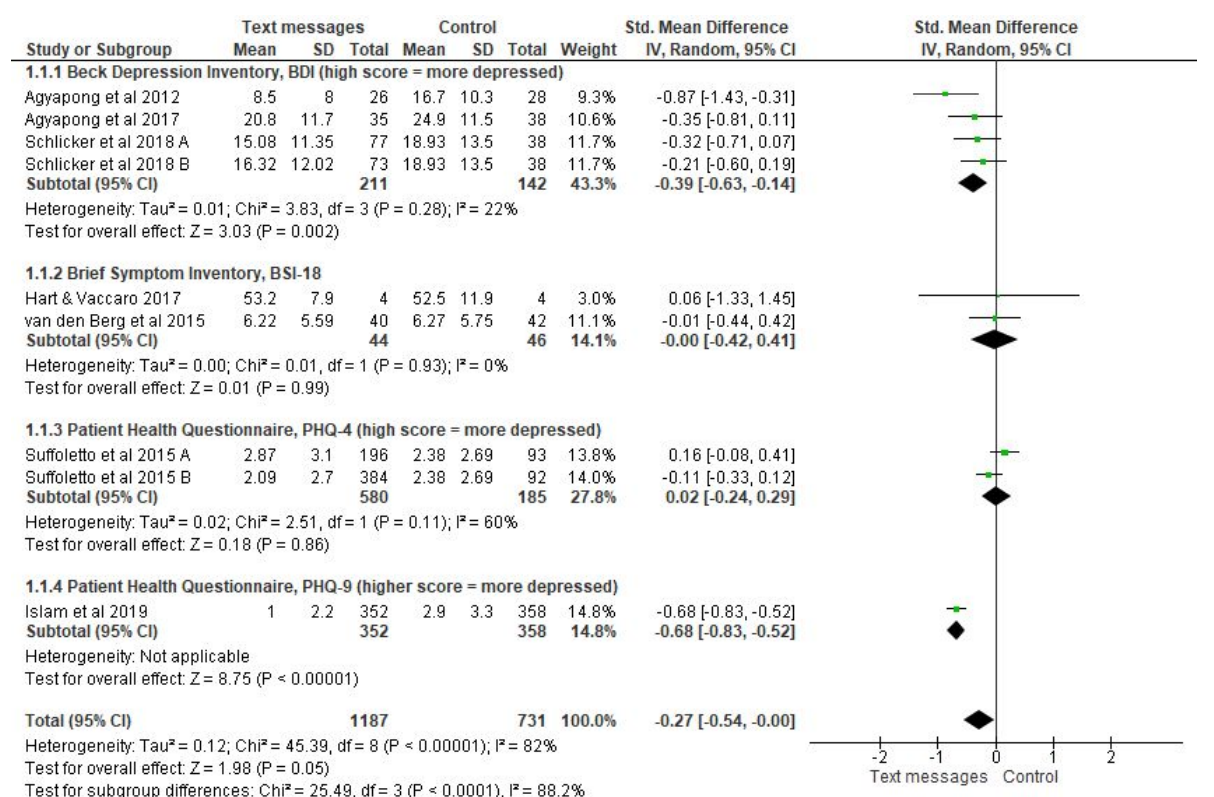

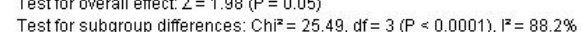


Figure 4. Forest plot of comparison: Text messages vs. control, content of the messages, Depression: mean scores at end of treatment.

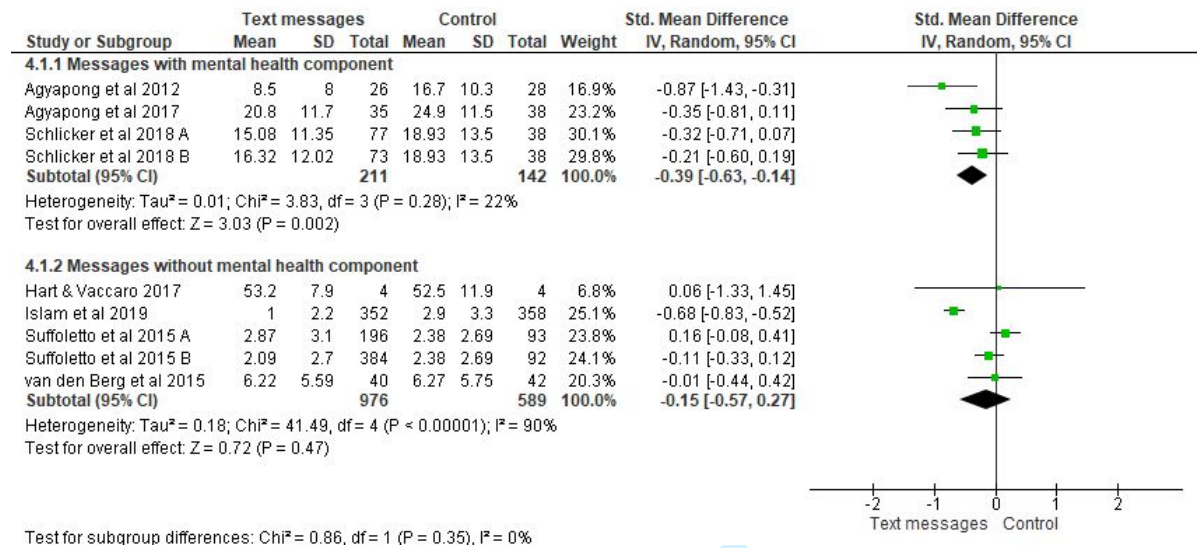

\footnotetext{
Test for subaroup differences: $\mathrm{Chi}^{2}=0.86, \mathrm{df}=1(\mathrm{P}=0.35), \mathrm{I}^{\mathrm{2}}=0 \%$
} 
Figure 6. Forest plot of comparison: 2 Text messages vs. control, studies with depression as primary outcome, outcome: 2.1 Depression: mean scores at end of treatment.

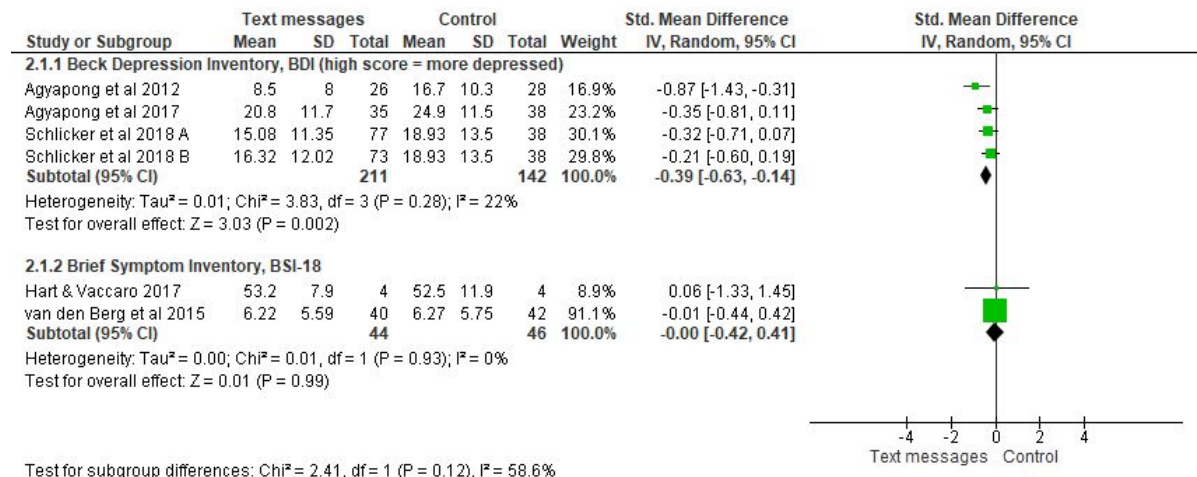

Test for subqroup differences: $\mathrm{Chi}^{2}=2.41, \mathrm{df}=1(\mathrm{P}=0.12), \mathrm{I}^{2}=58.6 \%$

Text messages Control 
Figure 7. Forest plot of comparison: 2 Text messages vs. control, studies with standard depression rating scales, outcome: 2.1 Depression: mean scores at end of treatment.

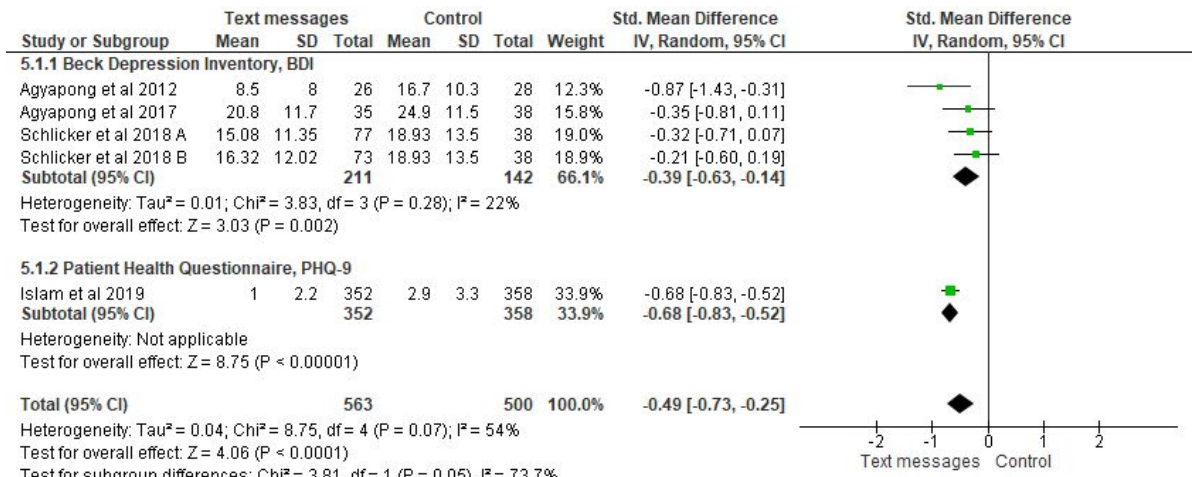

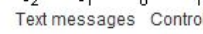


Table 1 Characteristics of the trials included in 'text messaging interventions for reducing symptoms of depression review'

\begin{tabular}{|c|c|c|c|c|c|}
\hline $\begin{array}{l}\text { First author, } \\
\text { year, country }\end{array}$ & $\begin{array}{l}\text { Target condition, study } \\
\text { duration }\end{array}$ & $\begin{array}{c}\text { Sample size, } \\
\text { mean age, } \\
\text { percent male }\end{array}$ & Experimental and control & $\begin{array}{c}\text { Depression tool } \\
\text { (primary/secondary } \\
\text { outcome measure) }\end{array}$ & $\begin{array}{l}\text { Outcomes, Endpoint } \\
\text { timing, Mean (SD) }\end{array}$ \\
\hline $\begin{array}{l}\text { Agyapong et al } \\
2012 \\
\text { Ireland }\end{array}$ & $\begin{array}{l}\text { DSM IV diagnosis of } \\
\text { unipolar depression } \\
\text { and AUD. Completed } \\
\text { an in-patient dual } \\
\text { diagnosis treatment } \\
\text { programme } \\
3 \text { months }\end{array}$ & $\begin{array}{l}54 \text { participants } \\
49 \text { years } \\
46 \%\end{array}$ & $\begin{array}{l}\text { Intervention group: twice daily } \\
\text { supportive text messages } \\
(\mathrm{n}=26) \\
\text { Control group: a fortnightly } \\
\text { thank you text message }(n=28)\end{array}$ & BDI-II (primary) & $\begin{array}{l}\text { End of intervention } \\
\text { Intervention } 8.5( \pm 8.0) \\
(n=196) \\
\text { Control } 16.7( \pm 10.3)\end{array}$ \\
\hline $\begin{array}{l}\text { Agyapong et al } \\
2017 \\
\text { Canada }\end{array}$ & $\begin{array}{l}\text { MDD } \\
3 \text { months }\end{array}$ & $\begin{array}{l}73 \text { participants } \\
\text { Not reported } \\
32 \%\end{array}$ & $\begin{array}{l}\text { Intervention group: twice-daily } \\
\text { supportive text messages } \\
\text { ( } n=35) \text {. } \\
\text { Control group: single text } \\
\text { message every fortnight } \\
\text { thanking them for } \\
\text { participating in the study } \\
(n=38)\end{array}$ & BDI-II (primary) & $\begin{array}{l}\text { End of intervention } \\
\text { Intervention } 20.8( \pm 11.7) \\
\text { Control } 24.9( \pm 11.5)\end{array}$ \\
\hline $\begin{array}{l}\text { Hart and Vaccaro } \\
2017 \\
\text { USA }\end{array}$ & $\begin{array}{l}\text { TBI sustained at least } 6 \\
\text { months prior and at } \\
\text { least mild depression } \\
\text { and/or anxiety } \\
8 \text { weeks }\end{array}$ & $\begin{array}{l}8 \text { participants } \\
29 \text { years } \\
50 \%\end{array}$ & $\begin{array}{l}\text { Intervention group: } \\
\text { individualized reminder } \\
\text { messages that were relevant } \\
\text { to ongoing goals, framed as } \\
\text { implementation intentions } \\
\text { sent daily by text message } \\
(n=4)\end{array}$ & BSI-18 (primary) & $\begin{array}{l}\text { End of intervention } \\
\text { Intervention } 53.2( \pm 7.9) \\
\text { Control } 52.5( \pm 11.9)\end{array}$ \\
\hline
\end{tabular}




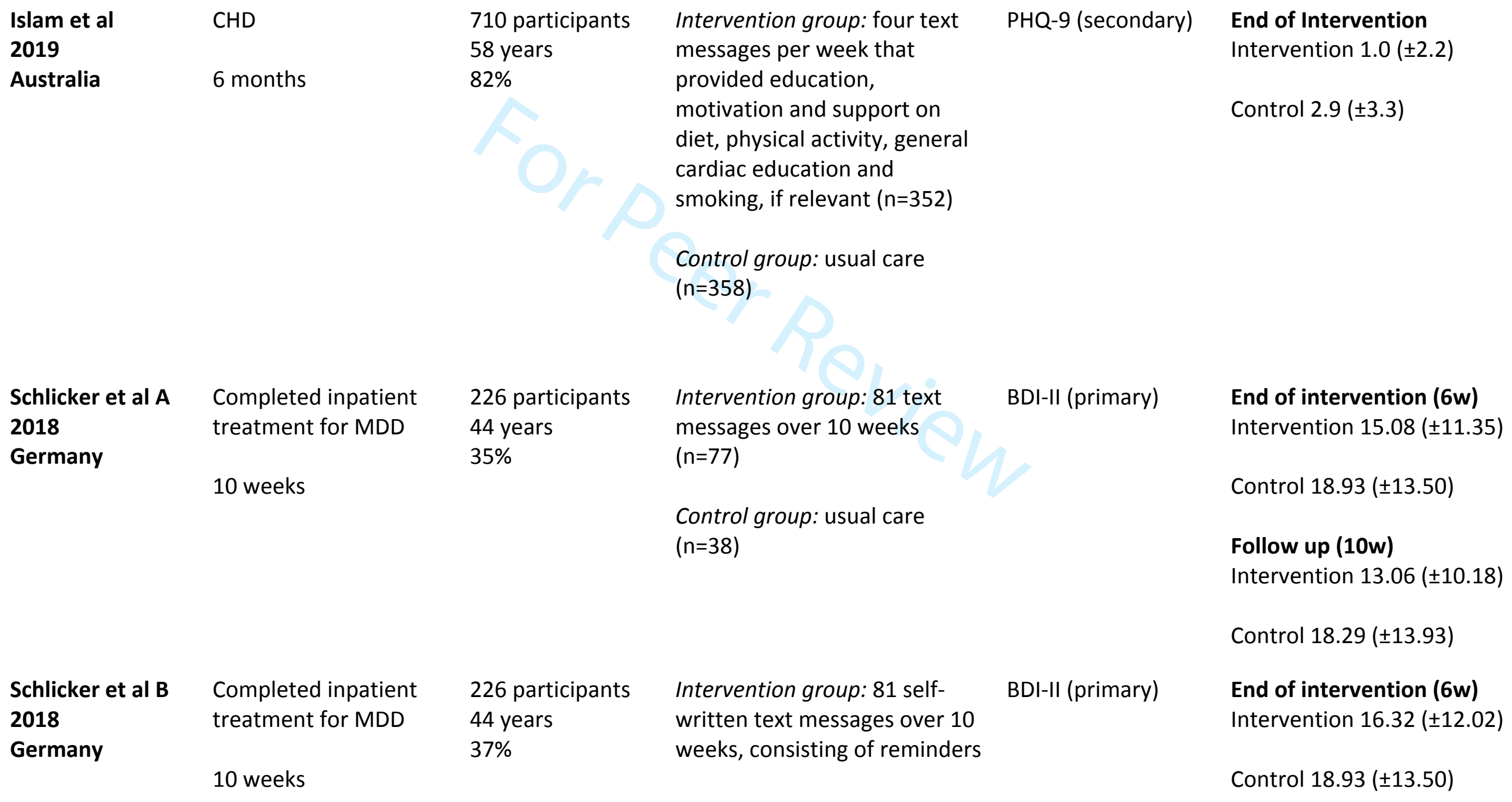

Control group: daily SMS

messages with self-selected

motivational statements

(motivation group, $\mathrm{n}=4$ )

Intervention group: four tex

motivation and support on

, physical activity, general

cardiac education and

Control group: usual care

$(n=358)$

Intervention group: 81 text messages over 10 weeks

Control group: usual care $(n=38)$

$( \pm 13.50)$ 
of what they learned in

inpatient CBT $(n=73)$

Control group: usual care $(n=38)$

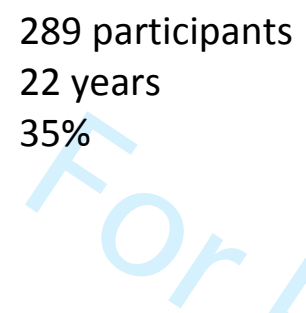

9 months
Aged $18-25$ years presenting to

emergency

departments who reported hazardous drinking
Intervention group: SMS SMS queried whether the

\section{Suffoletto et al B 2013}

USA
Aged $18-25$ years presenting to emergency departments who reported hazardous drinking

9 months drinking queries (assessing whether the individual had a weekend drinking plan). If a plan to drink was reported, person was willing to set a goal to limit drinking below the threshold of 4 drinks for women ( 5 for men) per drinking occasion over that weekend) $(n=196)$

Control group: usual care $(n=93)$

476 participants 22 years $35 \%$

intervention group: SMS plus feedback including: intention formation, barrier identification, general encouragement, goal setting, self-monitoring, positive feedback on performance, these two-way messages were

\section{Follow up (10w)}

Intervention $16.30( \pm 11.63)$

Control $18.29( \pm 13.93)$

PHQ-4 (secondary) End of Intervention (3m) Intervention $2.87( \pm 3.10)$

Control $2.38( \pm 2.69)$

\section{Follow up (6m)}

Intervention 2.95 ( \pm 3.21$)$

Control2.44 ( \pm 2.76$)$

\section{Follow up (9m)}

Intervention 2.59 ( \pm 2.09$)$

Control $2.69( \pm 3.15)$

PHQ-4 (secondary) End of Intervention (3m) Intervention $2.09( \pm 2.70)$

Control $2.38( \pm 2.69)$

Follow up $(6 \mathrm{~m})$

Intervention $2.19( \pm 2.65)$ 
interviewing styles. A

sequence of messages sent on

Thursday and another

\section{Follow up $(9 \mathrm{~m})$}

sequence on Sunday $(n=384)$

Intervention $2.11( \pm 2.75)$

Control group: usual care

Control $2.69( \pm 3.15)$

$(n=92)$

\section{Van den Berg et Preparing for discharge \\ with diagnosed \\ al \\ 2015 \\ depression, anxiety \\ disorder, adjustment \\ disorder or \\ somatoform disorder}

123 participants 44 years

$22 \%$

Intervention group: telephone calls and tailored once a week

short text messages $(n=40)$

Control group telephone calls only $(n=42)$

6 months

Abbreviations AUD: alcohol use disorder; DSM IV: Diagnostic and Statistical Manual of Mental Disorders, $4^{\text {th }}$ edition; BDI-II: Beck Depression Inventory, second revision; BSI: Brief symptom index; CBT: Cognitive Behavioural Therapy; CHD: coronary heart disease; m: months; MDD: major depressive disorder; PHQ-4: 4-item Patient Health Questionnaire; PHQ-9: 9-item Patient Health Questionnaire; PROMIS: Patient Reported Outcomes Measurement Information System; RCT: randomised controlled trial; SMS: short message service; TBI: traumatic brain injury; w: weeks. 
1

2

3

4

5

6

7

8

9

10

Table 2. Summary of findings table

\section{Text messages compared to control for Depression}

Patient or population: People with depression

Setting: Inpatient

Intervention: Text messages

Comparison: Control

\begin{tabular}{|c|c|c|c|c|c|}
\hline \multirow{2}{*}{ Outcomes } & $\begin{array}{l}\text { Anticipated absolute effects" }(95 \% \\
\mathrm{Cl})\end{array}$ & \multirow{2}{*}{$\begin{array}{l}\text { Relative effect } \\
\qquad(95 \% \mathrm{Cl})\end{array}$} & \multirow{2}{*}{$\begin{array}{l}\text { № of participants } \\
\text { (studies) }\end{array}$} & \multirow{2}{*}{$\begin{array}{l}\text { Certainty of } \\
\text { the evidence } \\
\text { (GRADE) }\end{array}$} & \multirow{2}{*}{ Comments } \\
\hline & $\begin{array}{l}\text { Risk with Text } \\
\text { messages }\end{array}$ & & & & \\
\hline $\begin{array}{l}\text { Depression: mean scores at end of } \\
\text { treatment }\end{array}$ & $\begin{array}{l}\text { SMD } 0.27 \text { SD } \\
\text { lower } \\
(0.54 \text { lower to } \\
0.00 \text { lower })\end{array}$ & - & $\begin{array}{c}1918 \\
(9 \mathrm{RCTs})\end{array}$ & $\underset{\substack{\text { VERY LOW } \\
\mathrm{a}, \mathrm{b}}}{\oplus \bigcirc \bigcirc}$ & \\
\hline $\begin{array}{l}\text { Depression: mean scores at end of } \\
\text { treatment }- \text { Beck Depression } \\
\text { Inventory, BDI (high score = more } \\
\text { depressed) }\end{array}$ & $\begin{array}{l}\text { SMD } 0.39 \text { SD } \\
\text { lower } \\
(0.63 \text { lower to } \\
0.14 \text { lower) }\end{array}$ & - & $\begin{array}{c}353 \\
(4 \mathrm{RCTs})\end{array}$ & $\underset{\text { VERY LOW c,d }}{\oplus \bigcirc \bigcirc \bigcirc}$ & \\
\hline $\begin{array}{c}\text { Depression: mean scores at end of } \\
\text { treatment - Brief Symptom Inventory, } \\
\text { BSI-18 }\end{array}$ & $\begin{array}{l}\text { SMD } 0 \text { lower } \\
\text { (0.42 lower to } \\
0.41 \text { higher) }\end{array}$ & & $\begin{array}{c}90 \\
(2 \mathrm{RCTs})\end{array}$ & $\underset{\substack{\text { VERY LOW } \\
\mathrm{a}, \mathrm{d}}}{\oplus \bigcirc \bigcirc}$ & \\
\hline $\begin{array}{l}\text { Depression: mean scores at end of } \\
\text { treatment }- \text { Patient Health } \\
\text { Questionnaire, PHQ-4 (high score = } \\
\text { more depressed) }\end{array}$ & $\begin{array}{l}\text { SMD } 0.02 \\
\text { higher } \\
(0.24 \text { lower to } \\
0.29 \text { higher })\end{array}$ & & & $\underset{\substack{\text { VERY LOW } \\
\mathrm{d}, \mathrm{e}}}{\oplus \bigcirc \bigcirc}$ & \\
\hline $\begin{array}{l}\text { Depression: mean scores at end of } \\
\text { treatment }- \text { Patient Health } \\
\text { Questionnaire, PHQ-9 (higher score = } \\
\text { more depressed) }\end{array}$ & $\begin{array}{l}\text { SMD } 0.68 \text { SD } \\
\text { lower } \\
\text { (0.83 lower to } \\
0.52 \text { lower) }\end{array}$ & - & $\begin{array}{c}710 \\
(1 \mathrm{RCT})\end{array}$ & $\bigoplus$ VERY LOW & \\
\hline
\end{tabular}

${ }^{*}$ The risk in the intervention group (and its $95 \%$ confidence interval) is based on the assumed risk in the comparison group and the relative effect of the intervention (and its $95 \% \mathrm{Cl}$ ).

Cl: Confidence interval; SMD: Standardised mean difference

\section{GRADE Working Group grades of evidence}

High certainty: We are very confident that the true effect lies close to that of the estimate of the effect

Moderate certainty: We are moderately confident in the effect estimate: The true effect is likely to be close to the estimate of the effect, but there is a possibility that it is substantially different

Low certainty: Our confidence in the effect estimate is limited: The true effect may be substantially different from the estimate of the effect

Very low certainty: We have very little confidence in the effect estimate: The true effect is likely to be substantially different from the estimate of effect

\section{Explanations}

a. We downgraded the quality of evidence as the studies were rated as high risk for multiple risk of bias domains.

b. We downgraded the quality of evidence as there is considerable heterogeneity (l= $75 \%$ to $100 \%)$ observed.

c. We downgraded the quality of evidence as the confidence intervals were wide.

d. We downgraded the quality of evidence as the confidence intervals were very wide.

e. We downgraded the quality of evidence as there are only 2 studies with $<100$ participants contributing to the analysis. 


\section{PRISMA 2009 Flow Diagram}

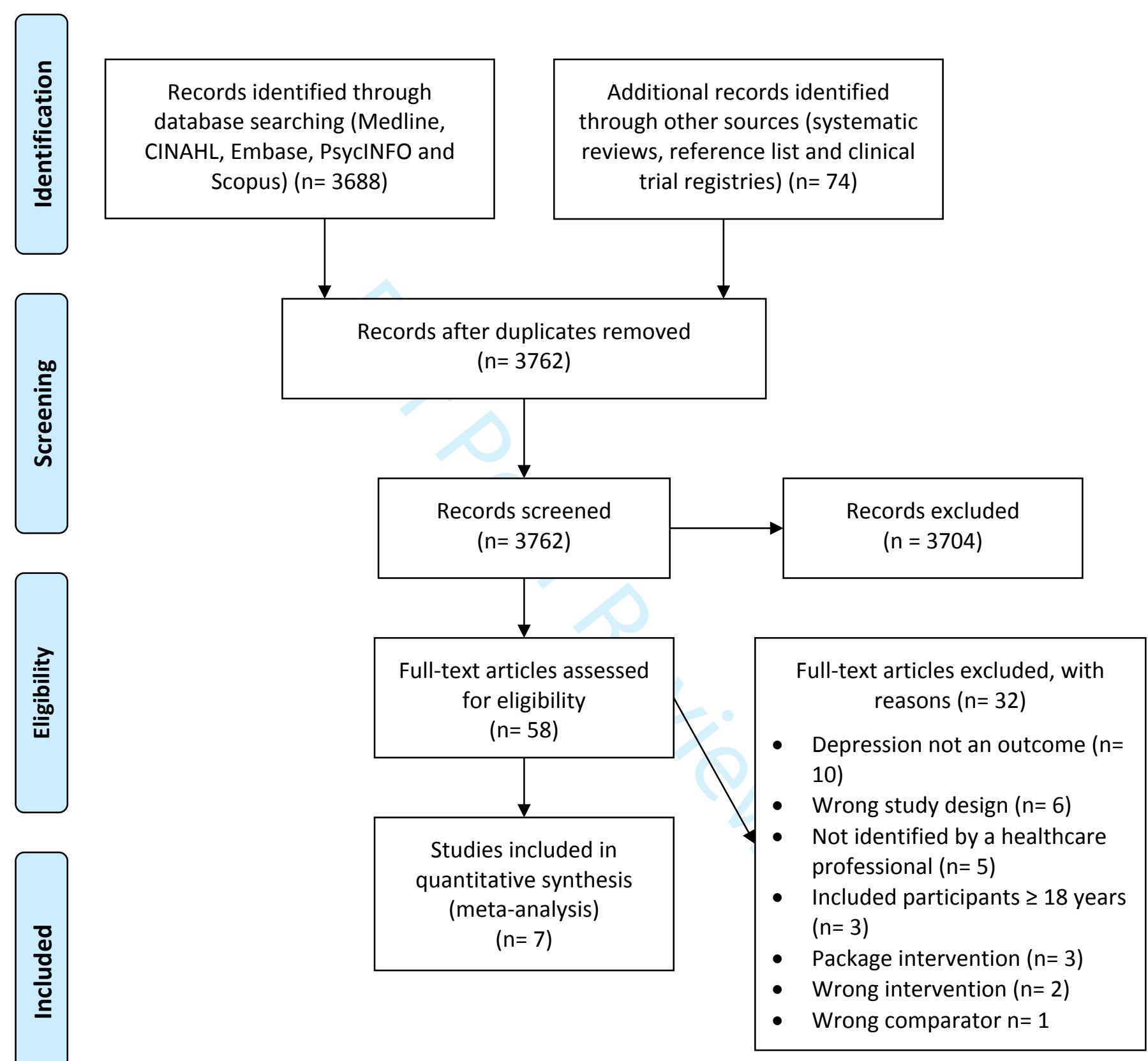

From: Moher D, Liberati A, Tetzlaff J, Altman DG, The PRISMA Group (2009). Preferred Reporting Items for Systematic Reviews and MetaAnalyses: The PRISMA Statement. PLoS Med 6(7): e1000097. doi:10.1371/journal.pmed1000097 


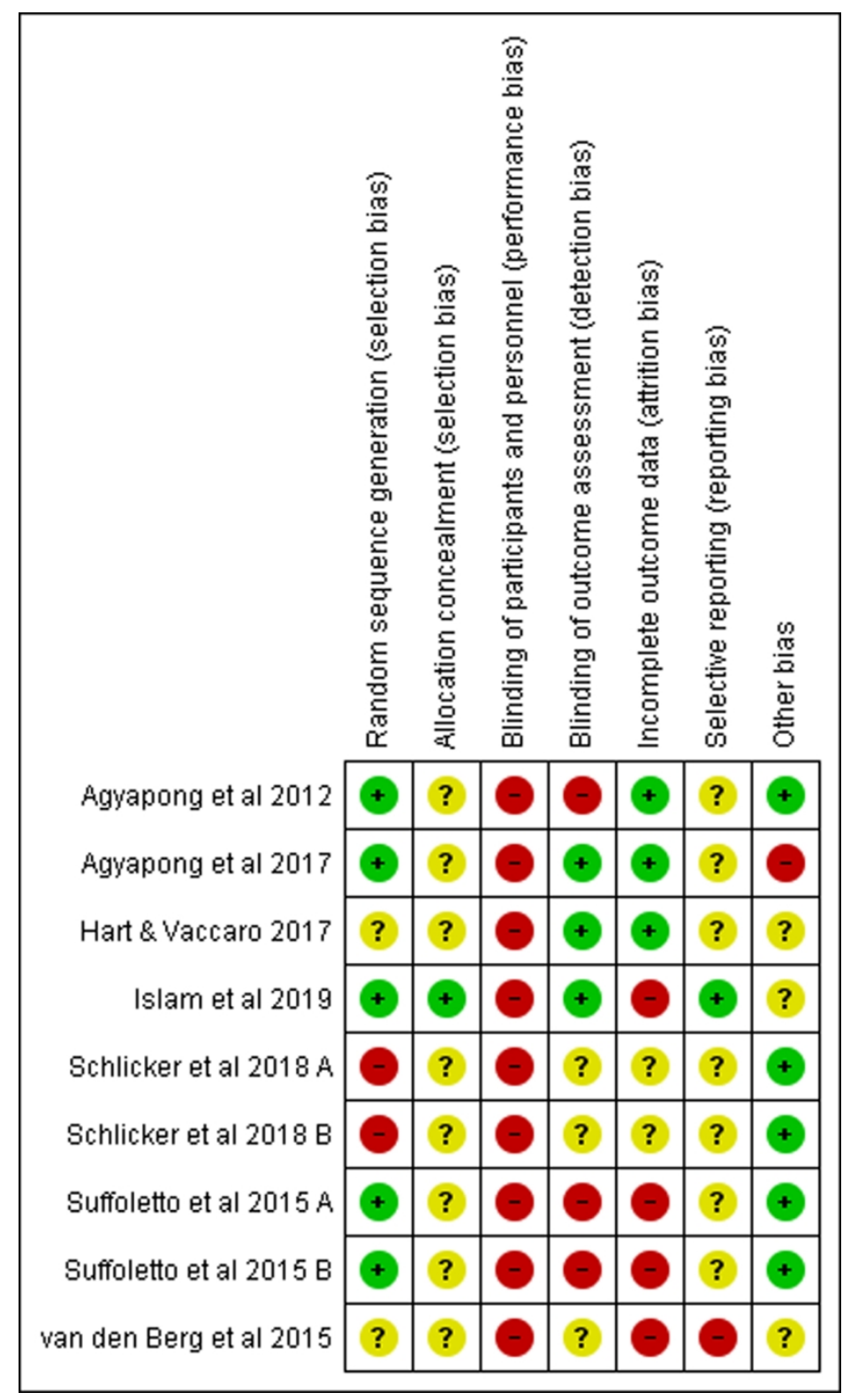

Figure 2 Risk of bias summary- review authors' judgments about each risk of bias item for each included study

$96 \times 161 \mathrm{~mm}(300 \times 300 \mathrm{DPI})$ 
Figure 3 Forest plot comparison- Text messages vs. control, Depression- mean scores at end of treatment. 


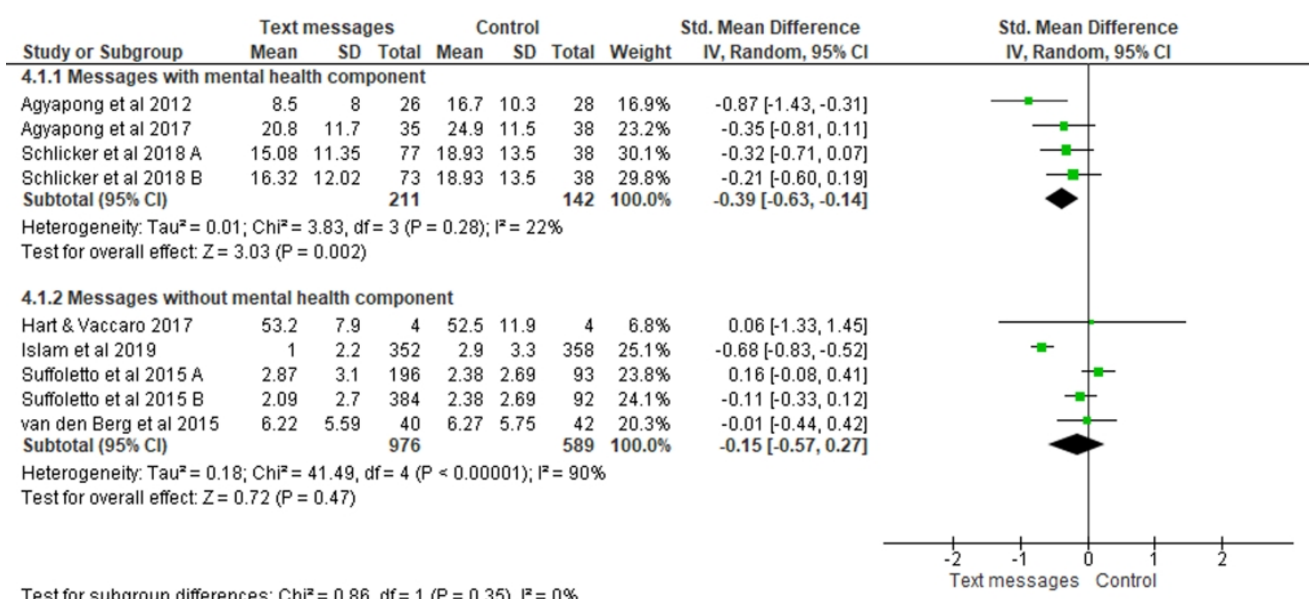

Figure 4 Forest plot of comparison- Text messages vs. control, content of the messages, Depression- mean scores at end of treatment.

$224 \times 101 \mathrm{~mm}(300 \times 300 \mathrm{DPI})$ 
Test for subqroup differences: Chi $^{2}=8.94 . d f=1(P=0.003) . l^{2}=88.8 \%$

Std. Mean Difference Std. Mean Difference IV, Random, $95 \% \mathrm{Cl}$ 3.1.1 >2 messages per wee Agyapong et al 2017 Hart \& Vaccaro 2017 Islam et al 2019 Schlicker et al $2018 \mathrm{~A}$ Schlicker et al 2018 B Suffoletto et al 2015

Control

$\begin{array}{lllllll}8.5 & 8 & 26 & 16.7 & 10.3 & 28 & 11.2 \%\end{array}$

$0.87[1.43,-0.31)$ $-0.35[-0.81,0.11]$ $0.06[-1.33,1.45]$ $-0.68[-0.83,-0.52]$ $-0.32[-0.71,0.07]$ $-0.21[-0.60,0.19]$ $-0.11[-0.33,0.12]$ $[-0.65,-0.13]$ Heterogeneity: Tau $^{2}=0.07 ; \mathrm{Chi}^{2}=21.97, \mathrm{df}=6(P=0.001) ;\left.\right|^{2}=73 \%$ Test for overall effect: $Z=2.96(P=0.003)$

3.1.2 $<2$ messages per week

$\begin{array}{llllll}\text { Suffoletto et al 2015 A } & 2.87 & 3.1 & 196 & 2.38 & 2.69\end{array}$ van den Berg etal $2015 \quad 6.22 \quad 5.59 \quad 40$ Subtotal $(95 \% \mathrm{CI})$

Heterogeneity: $\mathrm{Tau}^{2}=0.00 ; \mathrm{Chi}^{2}=0.46, \mathrm{df}=1(\mathrm{P}=0.50) ; \mathrm{I}^{2}=0 \%$

Test for overall effect: $Z=1.11(P=0.27)$

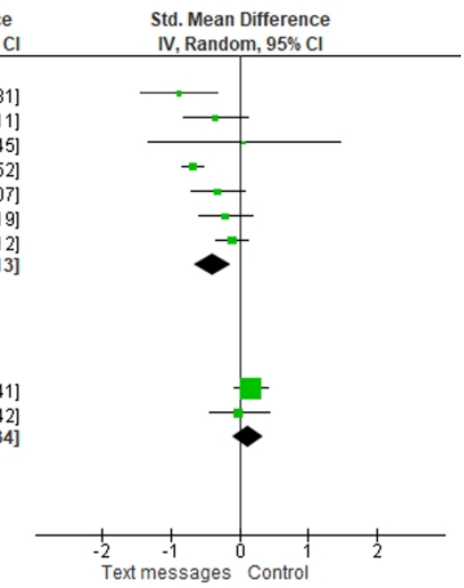

Figure 5 Forest plot of comparison- Text messages vs. control, frequency of messages, Depression- mean scores at end of treatment.

$224 \times 101 \mathrm{~mm}(300 \times 300 \mathrm{DPI})$ 


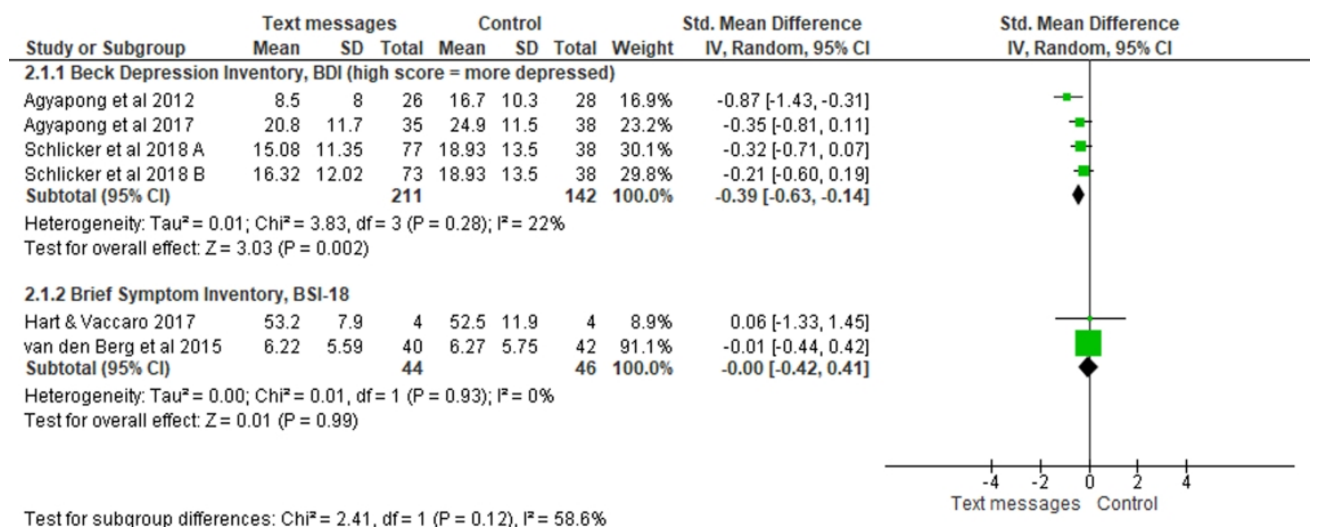

Figure 6 Forest plot of comparison- 2 Text messages vs. control, studies with depression as primary outcome, outcome- 2.1 Depression- mean scores at end of treatment.

\section{$224 \times 88 \mathrm{~mm}(300 \times 300 \mathrm{DPI})$}




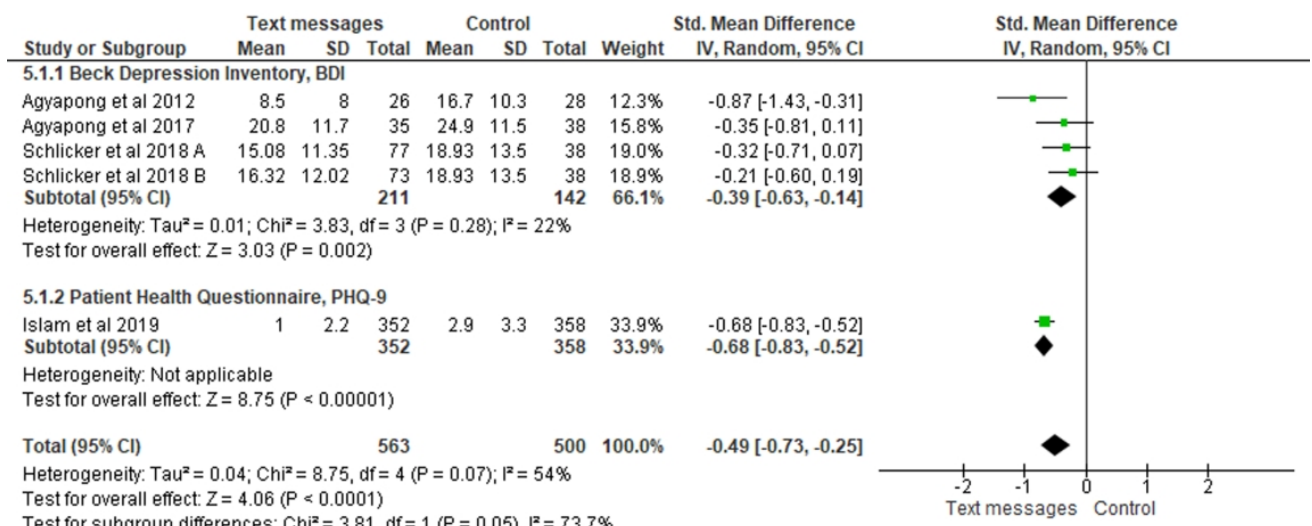

Figure 7 Forest plot of comparison- 2 Text messages vs. control, studies with standard depression rating scales, outcome- 2.1 Depression- mean scores at end of treatment.

\section{$221 \times 88 \mathrm{~mm}(300 \times 300 \mathrm{DPI})$}

